\title{
Plant responses to geminivirus infection: guardians of the plant immunity
}

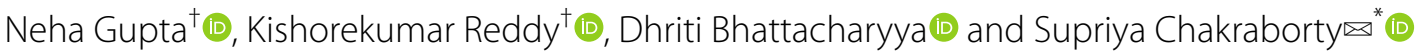

\begin{abstract}
Background: Geminiviruses are circular, single-stranded viruses responsible for enormous crop loss worldwide. Rapid expansion of geminivirus diversity outweighs the continuous effort to control its spread. Geminiviruses channelize the host cell machinery in their favour by manipulating the gene expression, cell signalling, protein turnover, and metabolic reprogramming of plants. As a response to viral infection, plants have evolved to deploy various strategies to subvert the virus invasion and reinstate cellular homeostasis.

Main body: Numerous reports exploring various aspects of plant-geminivirus interaction portray the subtlety and flexibility of the host-pathogen dynamics. To leverage this pool of knowledge towards raising antiviral resistance in host plants, a comprehensive account of plant's defence response against geminiviruses is required. This review discusses the current knowledge of plant's antiviral responses exerted to geminivirus in the light of resistance mechanisms and the innate genetic factors contributing to the defence. We have revisited the defence pathways involving transcriptional and post-transcriptional gene silencing, ubiquitin-proteasomal degradation pathway, protein kinase signalling cascades, autophagy, and hypersensitive responses. In addition, geminivirus-induced phytohormonal fluctuations, the subsequent alterations in primary and secondary metabolites, and their impact on pathogenesis along with the recent advancements of CRISPR-Cas9 technique in generating the geminivirus resistance in plants have been discussed.

Conclusions: Considering the rapid development in the field of plant-virus interaction, this review provides a timely and comprehensive account of molecular nuances that define the course of geminivirus infection and can be exploited in generating virus-resistant plants to control global agricultural damage.
\end{abstract}

Keywords: Autophagy, Begomovirus, Betasatellite, Defence, Geminivirus, Immunity, Pathogenesis, Resistance

\section{Background}

Geminiviruses belong to the largest family of plant viruses, Geminiviridae. Characterized by the circular, single-stranded DNA genome, they cause devastating diseases in plants, faring as one prominent reasons of global crop loss and compromised food security. Geminiviruses are phloem limited viruses and are transmitted

\footnotetext{
*Correspondence: schakraborty@mail.jnu.ac.in; supriyachakrasls@yahoo.com ${ }^{\dagger}$ Neha Gupta and Kishorekumar Reddy have contributed equally to this work.

Molecular Virology Laboratory, School of Life Sciences, Jawaharlal Nehru University, New Delhi 110067, India
}

by hemipterous insect vectors. Their unique virion includes a twinned icosahedral structure enclosing the circular genomic DNA. Replication of the DNA occurs through the rolling circle and recombination dependent mechanism [1]. In differentiated host cells, geminiviruses reprogram the cell cycle and transcriptional events [2], making the microenvironment suitable for its own replication. Inside the infected plant cell, host DNA polymerases convert the viral single-stranded DNA (ssDNA) into double-stranded DNA (dsDNA) and host nucleosomes pack the dsDNA forming minichromosomes that reside in host nucleus and can act as a template for virus transcription $[3,4]$. Early transcription events drive the genes original author(s) and the source, provide a link to the Creative Commons licence, and indicate if changes were made. The images or other third party material in this article are included in the article's Creative Commons licence, unless indicated otherwise in a credit line to the material. If material is not included in the article's Creative Commons licence and your intended use is not permitted by statutory regulation or exceeds the permitted use, you will need to obtain permission directly from the copyright holder. To view a copy of this licence, visit http://creativecommons.org/licenses/by/4.0/. The Creative Commons Public Domain Dedication waiver (http://creativeco mmons.org/publicdomain/zero/1.0/) applies to the data made available in this article, unless otherwise stated in a credit line to the data. 
essential for virus replication and transcription, followed by late genes required for encapsidation and movement. By altering the host gene expression profile and regulating the host cell signalling pathways, geminiviruses induce severe diseases in plants which manifest as leaf curling, veinal swelling, chlorosis, growth stunting, stem bending, and smalling of leaves etc. [5, 6].

Based on their phylogenetic relationships, genome organization, host range and insect vectors, geminiviruses are categorized into nine genera- Becurtovirus, Begomovirus, Capulavirus, Curtovirus, Eragrovirus, Grablovirus, Mastrevirus, Topocuvirus and Turncurtovirus [7]. Among these, begomovirus constitutes the largest genus that are predominantly transmitted by whitefly [Bemisia tabaci Genn.] vector. While majority of the classified genera comprises a monopartite genome, begomoviruses can contain either monopartite or bipartite genome. Based on their geographical distributions and genetic diversities, begomoviruses are grouped into Old world (Africa, Europe, Australia, and Asia) and New World categories (America) [8]. The New World begomoviruses mostly have bipartite genome while the Old World ones contain both mono and bipartite genomes. The genome of a bipartite begomovirus contains two separately encapsidated DNA molecules, known as DNA-A and DNA-B, of sizes ranging from 2600 to 2800 nt [8]. Monopartite begomoviruses have genome of one DNA molecule which is structurally and genetically similar to DNA-A of bipartite begomoviruses. Both DNA-A and DNA-B include a common region (CR) of 200-250 nucleotides that encompasses a conserved stem-loop structure and the sequence TAATATTAC. The DNA-A component contains open reading frames (ORFs) encoding five to seven proteins while DNA-B codes for two proteins. Two of the proteins in DNA-A of bipartite begomovirus and in monopartite virus are encoded in the virion sense strand and four in the complementary sense strand. The complementary sense strand proteins are replication-associated protein (REP; AC1), transcription activator protein (TrAP; AC2), replication enhancer protein (REn; $A C 3$ ), and $\mathrm{AC} 4$ protein. Coat protein $(\mathrm{CP}$; $\mathrm{AV} 1$ ) and precoat protein (AV2) are encoded in the virion sense strand. However, the AV2 ORF is absent in new world bipartite begomoviruses [9]. DNA-B contains ORFs BC1 and BV1 encoding movement protein (MP) and nuclear shuttle protein (NSP), respectively. The geminivirus proteins work in coordination to facilitate replication, movement, and anti-defence response to establish a successful infection process $[2,10,11]$.

In the infection establishment process, the subviral components of begomoviruses play important roles. Known as alphasatellite, betasatellite, deltasatellites or non-coding satellites, these satellite molecules depend on the helper virus for their replication and propagation, but some of them are adapted in modulating the biological properties of helper viruses $[5,12,13]$. While alphasatellites are self-replicating and depend on the helper virus for encapsidation, movement, and transmission, betasatellites are trans-replicated by helper begomovirus and mastrevirus [14-16]. With a genome of nearly $1350 \mathrm{nt}$, and two proteins $\beta \mathrm{V} 1$ and $\beta \mathrm{C} 1$ encoded in virion and complementary sense strand respectively, the betasatellites take important parts in symptom induction, host defence suppression and insect transmission [17-19]. Besides, betasatellites contain a satellite conserved region (SCR) and an adenine rich region important for betasatellite replication and maintenance [20, 21]. In natural conditions, plants can be infected by multiple viruses, and the stringency of betasatellites associated with their helper virus is very less, which increases the diversity of geminivirus-betasatellite complexes and enhances the probability of disease occurrence in new hosts. Furthermore, the high evolutionary rate of geminiviruses enables them to adapt to new hosts.

Due to the coevolution of plants and the pathogenic viruses, plants acquired multiple strategies to defend and counter viral infection and pathogenesis. However, viruses co-evolve to overcome such resistance responses [10]. Plants control the viruses by preventing the virus gene expression and inhibiting the systemic spread of viruses. Although inhibiting virus gene expression is one of the fundamental ideas of protecting the host from infection, the mainline defence against geminiviruses plays a crucial role in combating the geminivirus infections. This review deals with past and recent findings of major plant immune responses operated against the geminiviruses and a brief discussion on anti-host defence responses. Defence responses such as transcriptional gene silencing (TGS), post-transcriptional gene silencing (PTGS), autophagy, resistance genes and hypersensitive response (HR), protein kinase-mediated immunity, and ubiquitin-proteasome system are discussed in detail. In addition, regulation of phytohormones and alternations in plant primary and secondary metabolism during plant-geminivirus interactions are discussed, and host factors contribute to the pathogen resistance/tolerance are summarised.

\section{Main text \\ Transcriptional gene silencing and RNA polymerase blockers}

Plants deploy two major armours against geminiviruses that are based on silencing the expression of viral genes. While the methylation-mediated TGS targets viral minichromosomes, the viral mRNAs are rendered ineffective 
by PTGS. In the next two sections, we will present the nuances of these two processes.

Geminiviral DNA forms a complex with the coat protein and enters the nucleus. In the nucleus, using the host cell machinery the ssDNAs replicate to the double stranded forms and by binding with host's histones exist as the minichromosomes [3]. The plant's response to this invasion is employed by the RNA-directed DNA methylation ( $\mathrm{RdDM}$ ) apparatus to suppress the viral minichromosomes, silencing the viral gene expression by transcriptional gene silencing (TGS) $[22,23]$. This epigenetic silencing mechanism involves a sequence of host-virus interactions that reflect the different stages of the infection. In symptomatic tissue, during active replication/expression process, the minichromosomes exist in relaxed conformation, having a chromatin activation marker (H3K4me3) and low level of DNA methylation in comparison to the recovered tissue, where the minichromosomes bear the mark of chromatin-repression (H3K9me2) [24]. The cascade of silencing is operated by a section of small RNAs: siRNAs and miRNAs.

The canonical RdDM pathway is mediated by host DNA dependent RNA pol IV and V, which are evolved from RNA Pol II exclusively to function in plant RNA silencing pathways [25]. RNA Pol IV and V generate 24-nt siRNAs and amplify de novo methylation of target DNA [26]. Pol IV catalyses the formation of single-stranded non-coding transcripts from geminiviral chromatin which are replicated into dsRNA by RNA- DEPENDENT RNA POLYMERASE 2 (RDR2) by CLASSY 1 (CLSY1) dependent manner $[26,27]$. These dsRNAs are diced by DICER-LIKE 3 (DCL-3) ribonucleases and generates 24-nt siRNAs duplexes, which are stabilised by HUAENHANCER 1 (HEN1), later loaded onto ARGONAUTE 4 (AGO4)/AGO-6 containing RNA-induced silencing complex (RISC). When challenged with beet curly top virus (BCTV), the Pol IV-RdDM machinery reinforced and amplified the viral DNA methylation that was performed by a pathway involving RNA Pol II and RDR6 [26].

RNA polymerase $\mathrm{V}$ transcription is independent of siRNA biogenesis and carried out by DDR complex, which includes DEFECTIVE IN RNA DIRECTED DNA METHYLATION 1 (DRD1), DEFECTIVE IN MERISTEM SILENCING 3 (DMS3), REQUIRED FOR DNA METHYLATION 1 (RDM1) and DMS4. The siRNA present in the AGO4-RISC complex base pairs with the transcripts processed by Polymerase $\mathrm{V}$ activity. This interaction is stabilized by the AGO4 association with Nuclear RNA polymerase E (NRPE1) carboxyl-terminal tail and KOW DOMAIN-CONTAINING TRANSCRIPTION FACTOR 1 (KTF1) [28]. AGO4 further binds to RDM1 protein of DDR complex and recruits cytosine methyltransferase like DOMAINS REARRANGED METHYL TRANSFERASE 2 (DRDM2) to carry out de novo methylation on the viral genome [29]. Histone modification plays a decisive role in determining the course of host-virus interaction. A histone methyltransferase SU(VAR)3-9 HOMOLOGUE 4 (SUVH4), also known as KRYPTONITE2 establishes the specific repressive epigenetic markers such as histone methylation marks K9, K27 on $\mathrm{H} 3$ responsible for transcription repression ultimately results in TGS [29]. Histone methyltransferase KRYPTONITE (KYP) and DNA methyltransferase CHROMOMETHYLTRANSFERASE 3 maintain the TGS and to overcome this host-mediated TGS, virus-encoded transactivator AC2 activates an EAR-motif-containing transcription repressor RELATED TO ABI3 and VP1 (RAV2) that represses KYP expression facilitating virus survival in host [30].

The complex transcriptional reprogramming that involves DNA methylation and demethylation is central in the chromatin-based systemic immune responses in plant [31]. The epigenetic studies show the role of RdDM in resistance against geminiviruses [29, 32, 33]. Arabidopsis mutants $d d m 1$, ago4, drm1drm2, cmt3, adk1 and, $d c l 3$ that shows reduced viral genome methylation, are hypersusceptible to distinct geminiviruses [32]. However, geminivirus disease complexes overcome the TGS by virus-encoded TGS suppressors. For example, AC2 encoded transactivator protein (TrAP) of bipartite begomoviruses, V2 protein of tomato yellow leaf curl virus (TYLCV), and C2/L2 encoded TrAP of curtoviruses carry out the suppression of TGS pathway [34, 35]. V2 proteins of TYLCV and cotton leaf curl Multan virus (CLCuMuV) directly interact with AGO4 and interfere with binding of AGO4 to the viral DNA, functioning as TGS suppressor and promoter of virulence [36, 37]. Tomato leaf curl Yunnan virus (TLCYnV) encoded C4 protein binds to DOMAINS REARRANGED METHYLASE2 (DRM2) and hampers its binding to viral genome followed by antiviral DNA methylation [38]. Beet severe curly top virus (BSCTV) TrAP protein inhibits the proteasomal degradation of SAMDC1 (S-adenosyl-methionine decarboxylase). This disturbs the ratio of SAM (S-Adenosyl-methionine)/dSAM (decarboxylated SAM), which leads to inhibition of geminiviral DNA methylation [39]. Furthermore, TrAP protein inhibits ADK that is involved in the production of SAM, a methyl donor [34]. TrAP and $\beta C 1$ protein interact with SAHH (S-adenosyl homocysteine hydrolase), which is responsible for maintaining the methyl cycle during TGS [40] and dampens TGS. To increase the susceptibility, TYLCV pre-coat protein competes with Methytransferase 1 (MET1) and interacts with HISTONE DEACETYLASE 6 (HDA6) to repress DNA methylation [41]. On the plants' front, a 
total control of transposon elements and compaction of chromatin are achieved by Pol IV-RdDM mediated TGS of viral genome involving Pol IV and Pol V [42].

Post-translational modification of histone, an inherent gene expression regulatory process of plant is used by Arabidopsis against viral pathogens. EMSY-LIKE 1 (EML1) is a histone reader protein binds to H3K36 modification sites on viral chromatin blocking the access of RNA pol-II to the viral genes and suppressing the expression [42]. The access of RNA pol-II to viral genes is inhibited by Solanum lycopersicum regulatory particle triple-a atpase 4A (RPT4a), a subunit of 26-proteasome protein, that binds to the intergenic region of tomato leaf curl New Delhi virus (ToLCNDV), inhibiting the viral transcription [43].

All these molecular dynamics are inspiring developing newer strategies against geminivirus infections. Stable or transient expression of invert repeat constructs to the homologous sequence of geminivirus promoter region inhibits the expression of downstream genes and leads to the reduced viral load as well as symptom recovery. IR region/bidirectional promoter region has been successfully employed in generating the target-specific siRNA to downregulate the virus gene expression [44]. RNA-dependent RNA polymerase 1 (RDR1) of Nicotiana tabacum enhances cytosine methylation of tomato leaf curl Gujarat virus (ToLCGV) promoter and represses the virus gene expression and increases virus specific siRNA accumulation eventually leads to symptom remission [45]. Moreover, NtRDR1 overexpression in N. benthamiana alters the expression of host defence genes such as subunit-7 of COP9 Signalosome (CSN) complex, WRKY6 and USPA-like protein and confers reduced susceptibility to ToLCGV infection [46]. Administration of bidirectional promoter fragment from DNA-A of vigna mungo yellow mosaic virus (VMYMV) into VMYMV infected $V$. mungo plants abolished viral DNA accumulation and lead to disease recovery [47].

\section{Post transcriptional gene silencing}

The RNA transcripts produced by the viruses are targeted by the cytoplasmic siRNA-mediated silencing pathway of plant. This post-transcriptional gene silencing (PTGS) is a sequence-specific mechanism, is crucial for the host gene expression, development and defence [48]. In response to viral transcripts inside the cells, the PTGS initiates to target the dsRNA segments derived from either complementary viral transcripts (usually the products of bidirectional transcription) or viral RNA secondary structures like hairpins. DICER- LIKE protein (DCL) and dsRNA binding protein (DRB) recognise and process the dsRNAs into 21-24-nt siRNAs. HUA ENHANCER 1 (HEN1) protein methylates $3^{\prime}$ end of siRNAs and protects them from $3^{\prime}$ to $5^{\prime}$ exonucleolytic degradation and uridylation [49]. Alongside, these small RNAs duplexes are recruited onto AGO proteins to provide sequence specificity for targeting and forms RISC complex, resulting into mRNA degradation by cytoplasmic exonucleases or translation inhibition [50]. A second wave of amplified PTGS is generated at the systemic sites by the primary siRNAs to induce systemic resistance [25]. To counter this robust immunity response, geminiviruses have co-evolved several suppressors which interfere at multiple stages of the siRNA pathways such as sensing and activation of PTGS, siRNA biogenesis, amplification and systemic spread to mitigate the host defence [51]. Nuclear shuttle protein (NSP), encoded by the ORF BV1, induces ASYMMETRIC LEAVES2 (AS2) expression in the infected cells that enhances the decapping activity of DECAPPING 2 (DCP2), accelerating the mRNA turnover and hindering siRNA accumulation as well as host RNA silencing [52]. An endogenous RNAi suppressor calmodulin-like protein $(\mathrm{CaM})$ is upregulated by $\beta \mathrm{C} 1$ protein, triggering an interaction cascade that leads to degradation of Suppressor of Gene Silencing 3 (SGS3) and suppression of RDR6 activity, eventually affecting the anti-viral RNA silencing process $[53,54]$. Rep protein of wheat dwarf virus (WDV) binds to $21 \mathrm{nt}$ and $24 \mathrm{nt}$ siRNAs duplexes, inhibiting local and systemic silencing of viral RNA and spread of signals [55]. TYLCV infected and cotton leaf curl Mul$\tan$ betasatellite (CLCuMuB) $\beta \mathrm{C} 1$ expressing transgenic plants showing increased expression of AGO1 and DCL1 underscore the nuanced anti-PTGS process in play [56]. $\mathrm{CLCuMuV} \mathrm{C4}$ interacts with the core enzyme of methyl cycle, S-adenosyl methionine synthetase (SAMS) to inhibit TGS and PTGS and, C4 ${ }^{\mathrm{R} 13 \mathrm{~A}}$ mutant fails to retain the suppressor activities [57]. SAMS utilises ATP for converting the methione to SAM [58]. Intriguingly, the arginine 13 of cotton leaf curl Kokhran Virus-Dabawali (CLCuKV-Dab) C4 protein had shown to be important for ATPase function [59]. Presumably CLCuMuV C4 exerts its ATPase action to inhibit the SAMS activity.

Exploitation of host PTGS constitutes a promising strategy in rising the potential defence strategies against geminivirus. In fact, this strategy successfully introduced three decades ago, for developing resistance against a plant RNA virus, tobacco mosaic virus (TMV), where the transgenic expression of TMV CP protein delayed the disease progression [60]. Similar result was also observed with TYLCV. However, the protection was dependent on the expression of the transgene in infected CP transgenic tomato plants [61]. Recombinant vector-mediated expression of artificial dsRNAs raised from either conserved or fusion transcripts belong to same or different virus origin triggers siRNA accumulation and potentially 
triggers PTGS against broad spectrum geminiviruses [62, 63].

\section{MicroRNAs in antiviral immunity}

MicroRNAs (miRNAs) play a significant regulatory role in plant development as well as biotic and abiotic stress responses. In plants, miRNA biogenesis predominantly occurs in the following steps: (1) Transcription of primary miRNA from MIRNA (MIR) genes by RNA polymerase II, (2) Processing of primary miRNAs to nascent miRNA by Dicer-like proteins, (3) Methylation of nascent miRNA and assemble into RISC and, (4) Binding to target mRNA and regulation of gene expression [64]. Existing literature highlights the role of miRNAs against geminiviruses as an underexplored area with promising insights on several aspects of plant-virus interaction. Transient or transgenic expression of geminiviral proteins often exhibit phenotypic abnormalities, evidences the possible involvement of perturbations in miRNA regulatory pathways $[65,66]$. AC4 protein of african cassava mosaic virus (ACMV) directly binds to the matured miRNAs and interferes with the mRNA homeostasis that results into developmental abnormalities [66]. The reports on tomato yellow leaf curl Sardinia virus (TYLCSV) and mungbean yellow mosaic India virus (MYMIV) infection in tomato and mungbean, respectively highlighted the host miRNAs that targets phytohormone pathways, resistance (R) genes, receptor-like serine/threonine-protein kinases and transcriptions factors involved in the development [67, 68]. The influence of betasatellite on induction of host miRNA has been studied in the plants co-infected with tomato yellow leaf curl China virus (TYLCCNV) and tomato yellow leaf curl China betasatellite (TYLCCNB), in the presence and absence of functional $\beta C 1$. TYLCCNB responsive miRNAs such as miR391, miR397, and miR398 have been predicted to generate the phased secondary siRNAs (phasiRNAs) [69]. Bioinformatics analysis suggested the tendency of host miRNAs to bind to the geminiviral genome and ORFs and may negatively regulate viral transcription [70]. Prediction analysis of RNA hybrid software revealed $\mathrm{miR} / \mathrm{miR}^{*}$ sequences are capable of binding ToLCNDV ORFs includes AC1, AC2, AC3, AV1, AV2, BV1 and to betasatellite non-coding region at one or more than one site. Nonetheless, still virus dominates the host defence response by successfully deploying its silencing suppressors [70]. Transgenic plants expressing miRNAs specific to AV1 and AV2 proteins confer tolerance to tomato leaf curl virus (ToLCV), indicating the effectiveness of miRNAs against geminiviruses [71]. Gossypium hirsutum miR398 and miR2950 were found to bind to the genomes of both CLCuMuV and $\mathrm{CLCUMB}$, and potentially augmented the $\mathrm{CLCuD}$ resistance in transgenic plants [72]. In silico analysis suggests the binding capability of Glycine max miRNAs on the genome of MYMIV and mungbean yellow mosaic virus (MYMV) but also involves in regulation of plant defence responses [73]. A stable barley transgenic line, developed with a polycistronic artificial miRNA, gains the resistance against WDV at a lower temperature ranging between $12-15{ }^{\circ} \mathrm{C}$ [74]. Recently, ToLCV resistant tomato transgenic lines have been generated by overexpressing the ATP binding domain of AC1 protein via artificial miRNA without compromising the yield [75]. Expression analysis of miRNAs sheds light on possible role of Argonaute homeostasis along with miRNA directed cleavage of virus movement protein in developing resistance against viruses along with the gene regulatory changes in hormonal signalling pathways [76]. Greater supplementary research is required to understand miRNAs as a potential tool in rising defence against geminiviruses.

\section{Ubiquitin-proteasomal pathway and SUMOylation}

Ubiquitination is a post-translational modification process, where the protein ubiquitin is conjugated to the lysine moiety of a target protein and eventually directs the protein to $26 \mathrm{~S}$ proteasomal degradation. Ubiquitination requires the sequential action of three enzymesubiquitin-activating enzyme (E1), ubiquitin-conjugating enzyme (E2), and E3 ubiquitin ligase (E3). One of the most abundant E3 ligase families comprises Cullin Ring Ligases (CRLs) in SCF complex (SKP1-CUL1-F-boxprotein) which is regulated by CSN complex. The F-box proteins contribute to hormonal regulations of plants [77]. The F-box protein CORONATIN INSENSITIVE 1 (COI1) $\left(\mathrm{SCF}^{\mathrm{COI1}}\right)$, functions as one of the components of the jasmonic acid (JA) receptor, is involved in pathogenesis in plants. Upon pathogen infection, increased accumulation of jasmonoyl isoleucine (JA-Ile) facilitates the interaction of repressor protein JAZ (Jasmonate Zim domain) with $\mathrm{SCF}^{\mathrm{COI} 1}$ which cause degradation of JAZ proteins, and elevated the expression of JA responsive genes [78] that were earlier repressed by JAZ.

In plants, the quality control process of protein involving proteases, autophagy and proteasomal degradation systems work closely with defence pathway that requires degrading the pathogenic proteins $[79,80]$. During geminivirus infection, aggregation of viral proteins in the cytosol and nucleus [81, 82] is reported often. These aggregates sequester the viral proteins and virion particles from the host immune sensors to ensure the survival, multiplication and movement of the viruses [83]. A number of reports suggest that Ubiquitin-proteasomal pathway regulates geminiviral infection by degrading either viral or cellular proteins $[79,84,85]$. NtRFP1, a tobacco RING -finger protein, which functions as a ubiquitin E3 ligase interacts with $\beta C 1$ protein and mediates 
$\beta C 1$ ubiquitination, attenuating betasatellite mediated symptom expression [79] (Fig. 1). Ubiquitin activating enzyme (UBA1) interacts with TrAP protein and silencing of UBA1 promotes early viral infection in transgenic $N$. benthamiana [85]. TYLCV TrAP protein also regulates $\mathrm{CSN}$ activity to inhibit $\mathrm{SCF}^{\mathrm{COI1}}[86]$. $\beta \mathrm{C} 1$ protein interrupts SKP1 and CUL1 interaction during CLCu$\mathrm{MuV}$ infection disrupting the proteasomal degradation pathway and altering plant hormonal signalling cascades [87]. S. lycopersicum E2 enzyme UBC3 (Ubiquitin-conjugating enzyme 3 ) activity is also blocked by $\beta C 1$, with aftermath of decreased level of total polyubiquitinylated protein and increased symptom severity [88]. Cyclindependent kinase/cyclins control cell cycle progression in plants and animals. CDK inhibitors (CKIs) negatively regulate CDK/Cyclins. One of the mammalian CKIs, CKI p27kip1, is degraded through the help of ubiquitin ligase KPC (Kip-1 ubiquitination promoting complex). Expression of C4 gene of BSCTV in Arabidopsis induces Ring finger protein RKP1 the protein similar to human KPC1. RKP1 acts as an ubiquitin E3 ligase and interacts with CKIs, thus lowering the protein level of CKIs during the infection with the effect of continued cell cycle progression [84]. BSCTV also couples ubiquitin-proteasomal system (UPS) to TGS defence pathways, hampering the latter [39]. Numerous molecular studies also revealed the involvement of UPS in regulating the immune responses by altering the fate of transcriptional regulators [77], virus replication [89] and, movement [90]. However, these roles need to be ascertained in the context of geminivirus infection.

SUMOylation is a transient, post-translational modification, similar to ubiquitination and is involved in ligation of a $10 \mathrm{kDa}$ small ubiquitin-related modifier, SUMO to the lysine residues of target peptides to modulate protein activities and interaction as well as subcellular localization [91]. The dynamic equilibration of SUMOylation plays a crucial role in development [92], biotic and abiotic stress responses [93] of plants. Interactions of SUMO conjugating Enzyme $1 \mathrm{~A}$ (NbSCE1), E2-SUMO conjugating enzyme of $N$. benthamiana, with $\mathrm{N}$-terminal of Rep proteins of tomato golden mosaic virus, (TGMV), TYLCSV, and ACMV are vital for virus replication $[94,95]$. In plant RNA virus infection, interaction of SCE1 and viral replicases has a similar positive-effects on virus replication [96]. The interaction between NbSCE1 and Rep/AL1 protein in both monopartite and bipartite begomoviruses augments virus replication, probably by altering the SUMOylation patterns of specific host factors to create a favourable environment for the viruses [95]. SUMOlyation of proliferating cell nuclear antigen (PCNA), the replication processivity factor is compromised by the Rep protein creates a similar permissive ambience for geminivirus replication [97]. Synedrella yellow vein clearing virus (SyYVCV)- $\beta C 1$ undergoes via ubiquitination mediated degradation [91]. The N-terminal SUMOylation motifs of $\beta \mathrm{C} 1$ functions as stability markers whereas the C-terminal SUMO interacting motifs (SIMs) binds to the host cellular components, promoting the protein degradation. To counter the host-mediated degradation, $\beta C 1$-protein interacts with $N b S U M O 1$ and recruits the host SUMOylation machinery. Both $\mathrm{N}$-terminal and C-terminal SUMOylation motifs of $\beta \mathrm{C} 1$ are indispensable for the symptom expression, virus replication and systemic movement. However, chloroplast localization of $\beta C 1$ solely depends on C-terminal SUMOylation motifs [91]. Further research is required to explore how the plants engage the defence response to counteract such virus induced microenvironmental modifications.

\section{Autophagy as a viral venator}

Autophagy is an evolutionary conserved process of recycling the degraded or undesirable cellular components taking place in the cell. Autophagic cargo sequestered into vesicle-like compartments and subsequently fused

\footnotetext{
(See figure on next page.)

Fig. 1 Schematic overview of plant immune strategies against geminiviruses. Geminivirus infection initiates with the release of viral ssDNA into the nucleus, subsequently leads to the replication, transcription and translation of viral genome. (A) Plants counteract geminivirus genetic life cycle via multiple host factors. GRAB interacts with RepA and interferes with the replication. RPT4a and EML1 hamper the geminivirus active transcription by obstructing the RNA Pol-II on virus euchromatin. Additionally, host induces RNAi via TGS and PTGS to suppress the viral gene expression. Virus-encoded VSRs potentially suppresses the RNAi. (B) Geminivirus induced GRIK1 autophosphorylates and activates SnRK1 which interact and phosphorylates the viral Rep, TrAP (AL2/C2) and $\beta C 1$ protein. Phosphorylation of Rep and TrAP impedes Rep binding and causes a delay in the infection, respectively. $\beta C 1$ phosphorylation hampers the TGS and PTGS suppressor functionalities and attenuates symptom expression via suppression of AS1- $\beta C 1$ mediated downstream responses. Phosphorylated $\beta C 1$ may also direct to autophagy. (C) Tobacco RFP1 interacts with $\beta C 1$ and prompts the $\beta C 1$ degradation via ubiquitin-mediated 265 proteasomal pathway and causes the symptom attenuation. (D) ATG8h interacts with nuclear C1 and translocate to cytosol Xpol dependent manner. The ATG8h-C1 complex is then recruited into autophagosomes with the aid of ATG5 and ATG7 for vacuolar degradation. (E) Defence regulated MEKK1-MKK1/MKK2-MPK4 module induced, activated by geminivirus infection and exerts the basal defence response. However, $\beta C 1$ protein directly interacts with MKK2 and MPK4, thereby suppress the broad spectrum of downstream defence reactions. (F) NIK-1 from plasma membrane activated upon the geminivirus infection triggers dimerization and autophosphorylation. Alternatively, PTI induced DAMPs secreted from ER in response to virus attack may cause NIK-1 activation. Active NIK-1 phosphorylates and translocate L10 into the nucleus where it binds to LIMYB to block the transcription of ribosomal biosynthesis genes which affects the global translation and prevents the translation of viral genes
} 


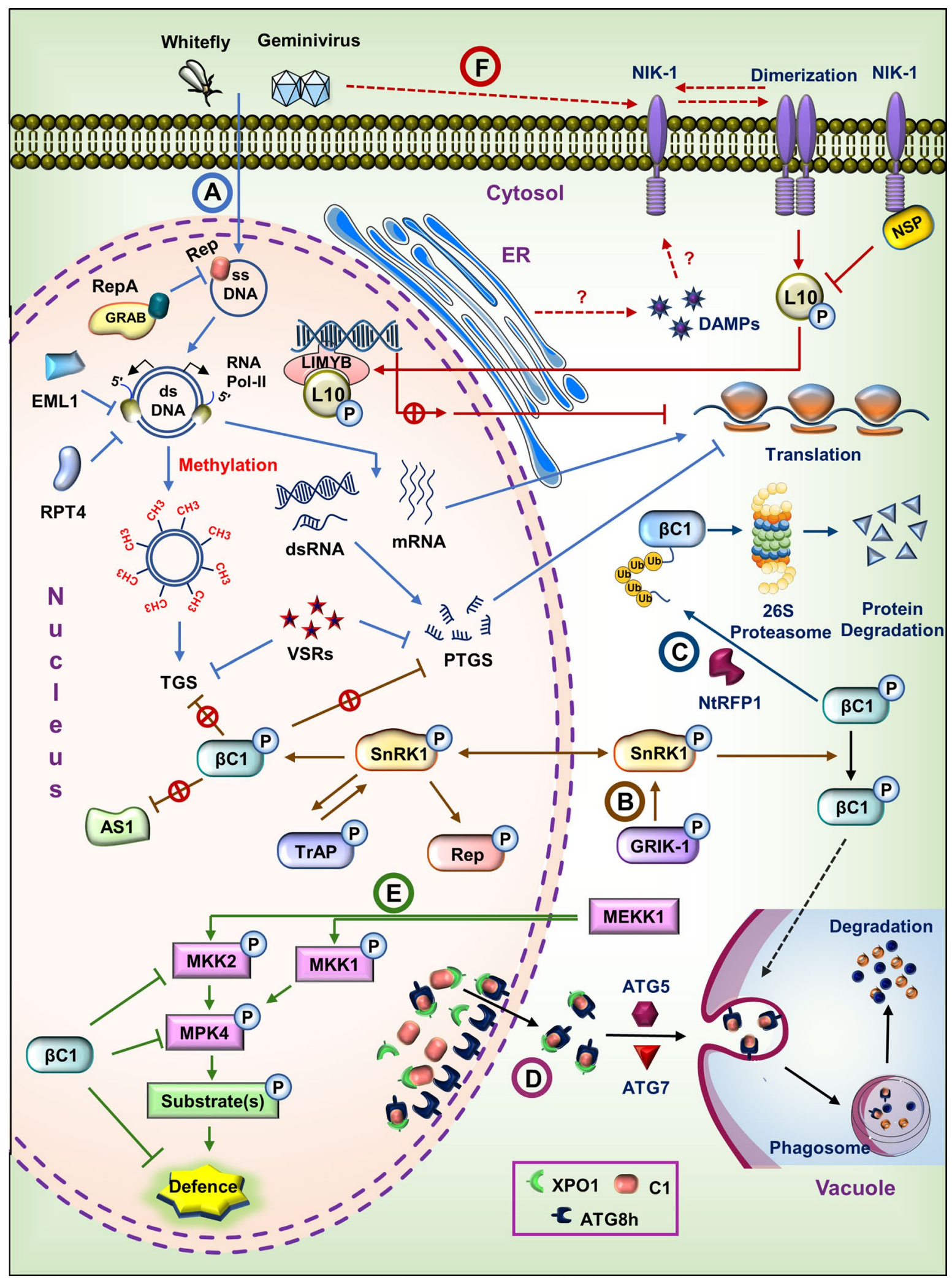

Fig. 1 (See legend on previous page.) 
with lytic components such as lysosomes in animals and vesicles in the plant cells. Studies conducted on plant DNA and RNA viruses confirm that autophagy plays a potential antiviral role in host innate and adaptive immunity $[98,99]$. In vivo and in vitro experiments showed that $\mathrm{CLCuMuB} \beta C 1$ protein interacts with autophagyrelated protein NbATG8 through its ATG8 interacting motif (LVSTKSPSLIK) and directs it for degradation. Disruption of $\beta C 1$-ATG8 interaction by a point mutation (V32A) in the ATG8 interaction motif promotes the virus replication and disease symptoms. Since ATG genes are functionally redundant, silenced ATG5 and ATG7 transgenic plants when infected with CLCuMuV and associated betasatellite showed severe and early symptoms [98]. Furthermore, interaction of ATG8h protein with Rep protein of TLCYnV leads to ATG8h mediated Rep translocation to cytoplasm and degradation [80] (Fig. 1).

Autophagy carries out both pro-viral and anti-viral roles in host cells to maintain the balance of cellular and viral proteomes. Geminiviruses have recently been reported to manipulate autophagy-mediated defence by inducing autophagy of host factors involved in other defence pathways. TYLCCNB-encoded $\beta C 1$ regulates Nbrgs-CaM, which induces degradation of NbSGS3 with the help of ATG factors [54]. $\beta C 1$ protein of CLCuMuB disrupts the interaction between a negative autophagic regulator and ATG3 protein to induce autophagy in Nicotiana benthamiana [100]. Further research is needed to reveal the mechanism behind the regulation of autophagy during viral infection and explore the potential of blocking proviral autophagic pathways as a mean to control the infection.

\section{Kinases as transducers of defence}

Protein kinases are some of the key components involved in plant growth, development and defence including pathogen sensing and defence response induction [101]. Protein kinases are accountable for setting different signalling cascades in motion for efficient plant defence against geminiviral infection [102-104]. Viral proteins modulate the signal transduction pathways via both direct and indirect interactions with different host protein kinases. This section illustrates various mechanisms by which protein kinases such as SnRK1, MAP kinases and receptor like kinases (RLKs) orchestrate the cellular responses during plant-virus interactions.

\section{SnRK1 mediated signalling}

The SUCROSE NON-FERMENTING1-related protein kinase 1 (SnRK1) is a Ser/Thr kinase that functions as an energy sensor and central regulator of energy, metabolism and stress responses. It operates multi organellar crosstalk and potentially regulates downstream transcription factors involved in diverse molecular pathways to maintain cellular homeostasis [105]. Upon cabbage leaf curl virus (CaLCuV) and BCTV infection, functionally redundant geminivirus Rep interacting kinases GRIK1 and GRIK2 expression gets enhanced, which causes SnRK1 phosphorylation and activation [106]. GRIK1 and GRIK2 also interact with Rep protein of TGMV [107]. The lower expression of SnRK1 enhances the susceptibility of plants towards geminivirus, whereas SnRK1 overexpression leads to an increased resistance in plants [103]. SnRK1 phosphorylates TYLCCNB encoded $\beta C 1$ protein at serine 33 and threonine 78 residues, which negatively impacts the titres of both helper virus and betasatellite as well as disease development in $N$. benthamiana [108]. The phosphorylation of $\beta C 1$ also suppresses its role in suppression of methylation mediated RNA silencing, which further explains the significant role of SnRK1 against geminiviruses (Fig. 1). SnRK1 may also induce autophagy of $\beta C 1$ protein as yeast, and mammalian homologs of SnRK1 have been reported to promote autophagy by phosphorylation of different protein substrates $[98,109]$. AtREM4 (Arabidopsis thaliana remorin group 4), which functions as a positive regulator of the cell cycle during BCTV and BSCTV infections, gets phosphorylated by SnRK1 and induce the degradation of AtREM4 by $26 \mathrm{~S}$ proteasomal degradation pathway [110].

Geminiviral TrAP proteins AL2 from TGMV and L2 from BCTV interact with Arabidopsis SnRK1 and inhibit its activity to enhance pathogenesis [111]. SnRK1 maintains balance of cellular metabolic energy of host cells to defend against viral infection. Therefore, depletion of ATP or increased level of 5'-AMP activates SnRK1. As Adenosine kinase (ADK) phosphorylates adenosine to 5'-AMP, L2 and AL2 interact with ADK and disable the SNF1 kinase-related antiviral mechanism [111]. TrAP protein of $\mathrm{CaLCuV}$ also gets phosphorylated by SnRK1 at serine 109 position, which leads to delayed viral infection [33]. Further, SnRK1 phosphorylates TGMV-Rep at serine 97 position hindering binding of Rep onto the viral genome and inhibiting viral infection [112]. As suggested by the recent reports, being a global energy regulator of the cell and carrying out the role of metabolic modulator, SnRK1 has emerged as a pivotal player in plants antiviral defence armour.

\section{MAP kinase cascade}

Mitogen-activated protein kinase (MAPKs) are widely studied, and known to be involved in signal transduction and signal amplification processes and defence against diverse phytopathogens as well as in abiotic stresses [113]. MAPKs are activated by MAPK Kinase, which gets regulated through cross-phosphorylation. 
The role of MAPK cascades in plant innate immunity against bacterial and fungal pathogens is well studied [114]. New findings are highlighting the role of MPKs in antiviral defence responses, too. Vigna mungo MAPK1 has been found to suppress MYMIV accumulation and upregulate salicylic acid (SA) mediated expression of pathogenesis-related (PR) genes [115]. Similarly, MAPK3 silenced tomato plants showed reduced tolerance to viral infection and attenuated expression of SA/JA regulated defence related genes [116]. Earlier, global transcriptional analysis of whitefly after TYLCCNV infection revealed the downregulation of genes involved in MAPK signalling pathways [117]. TYLCCNV infection leads to activation of MAPK signalling cascade for defence, but $\beta C 1$ protein interacts with MKK2 and MPK4 inhibiting the kinase activity and limiting the anti-viral activity of MAPK [104] (Fig. 1). Recently, C4 mediated suppression of MAPK cascade activation has been discovered in $N$. benthamiana [118]. TLCYnV-encoded C4 competes with BRASSINOSTEROID INSENSITIVE 1 (BRI) to bind BRI1 KINASE INHIBITOR1 (BKI1) and stabilizes the protein complex on plasma membrane. The unavailability of free BIK1 precludes the autophosphorylation of ERECTA (ER), concomitantly leading to the inhibition of downstream MAPK cascade activation which facilitates optimal conditions for TLCYnV infection [118].

\section{Receptor-like kinases}

RLKs are transmembrane proteins that transduce extracellular signals by their specific ligand binding domains, a membrane-spanning region, and cytoplasmic serine-threonine kinase domain to regulate cell differentiation, patterning, development and innate immunity [119]. They act as pattern recognition receptors (PRRs) recognizing microbe-associated molecular patterns (MAMPs) and initiating the basal innate defence responses [119]. RLKs also recognize secondary danger signals produced in a stressed situation in the cells that boost the immune response against pathogens [120]. One of the RLKs, NSP interacting kinase (NIK) is encoded by a small multigenic family that consists of three genes NIK1, NIK2, and NIK3. Geminiviral nuclear shuttle protein (NSP) acts as a target of NIKs, implicating the existence of RLKs mediated immune response against geminivirus [121]. The plants deficient with $n i k$ exhibited enhanced susceptibility to begomoviruses infection [122]. Geminivirus infection triggers NIKs oligomerization and transphosphorylation of kinase domain at T474 that activates NIK1 kinase prompting the latter to phosphorylate the cytoplasmic ribosomal protein 10 (RPL10) [102]. As the phosphorylated RPL10 translocates into the nucleus with the transcription factor LIMYB (L10-interacting MYB domain-containing protein), it forms RPL10LIMYB complex that negatively regulate the virus infection by binding to the promoters of ribosomal protein gene and represses the expression (Fig. 1). However, the host NIKs mediated resistance against geminiviruses is limited by the NSP of geminiviruses as it interacts with NIKs and suppresses its activity [122] (Table 1). Another RLK, CLAVATA 1 (CLV1) that regulates WUSCHEL gene expression and helps in maintaining the meristem, undergoes binding by the S- acylated form of BSCTV C4 protein; an interaction leading to anomalous siliques development in Arabidopsis [123]. As it localizes to the plasmodesmata as well as to the plasma membrane, BARELY ANY MERISTEM 1 (BAM1) and BAM2 helps in expanding systemic movement of RNAi signals and thus obstructing the spread of the virus to other cells. However, TYLCV C4 protein binds to BAM1 and inhibits the propagation of silencing signals [124]. Arabidopsis Shaggy like kinase protein AtSK21, also known as AtBIN2 (Brassinoids inhibitor 2), negatively regulates brassinosteroid signalling and affects male sterility [125]. During sweet potato leaf curl virus (SPLCV) infection, viral C4 protein targets AtBIN2 inducing anomalous development including male sterility in Arabidopsis [125]. C4 physically interacts with RLKs, FLAGELLIN SENSING 2 (FLS2) and BRI1 and affect the downstream pathways as the interaction reduces the time of apoplastic ROS burst without influencing downstream marker genes

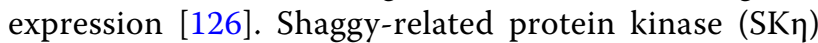
also determines $\mathrm{C} 4$ mediated symptom induction. The affinity of the NbSKn-C4 interaction and tethering to the plasma membrane complex regulates the viral pathogenicity [127]. RLK Proline-rich extension-like receptor kinase (PERK) like protein is exploited by the viral machinery to positively regulate viral protein NSP and enhancing the infection of tomato crinkle leaf yellows virus (TCrLYV) and TGMV. PERK can be considered as a potential resource to develop viral resistance in plants as T-DNA insertional mutation in PERK attenuates infection [128]. Various other RLKs like PHLOEM INTERCALATED WITH XYLEM members (PXYs), PEP1 RECEPTOR members (PEPRs) are some potential targets of viral C4 proteins. Manipulation of such RLKs which mediate defence and developmental processes by geminivirus points towards the possible roles of these RLKs in antiviral activity [129]. RLKs, being critically important in the perception of pathogens, need a broader exploration to reveal the molecular and genetic pathway against geminiviruses. 


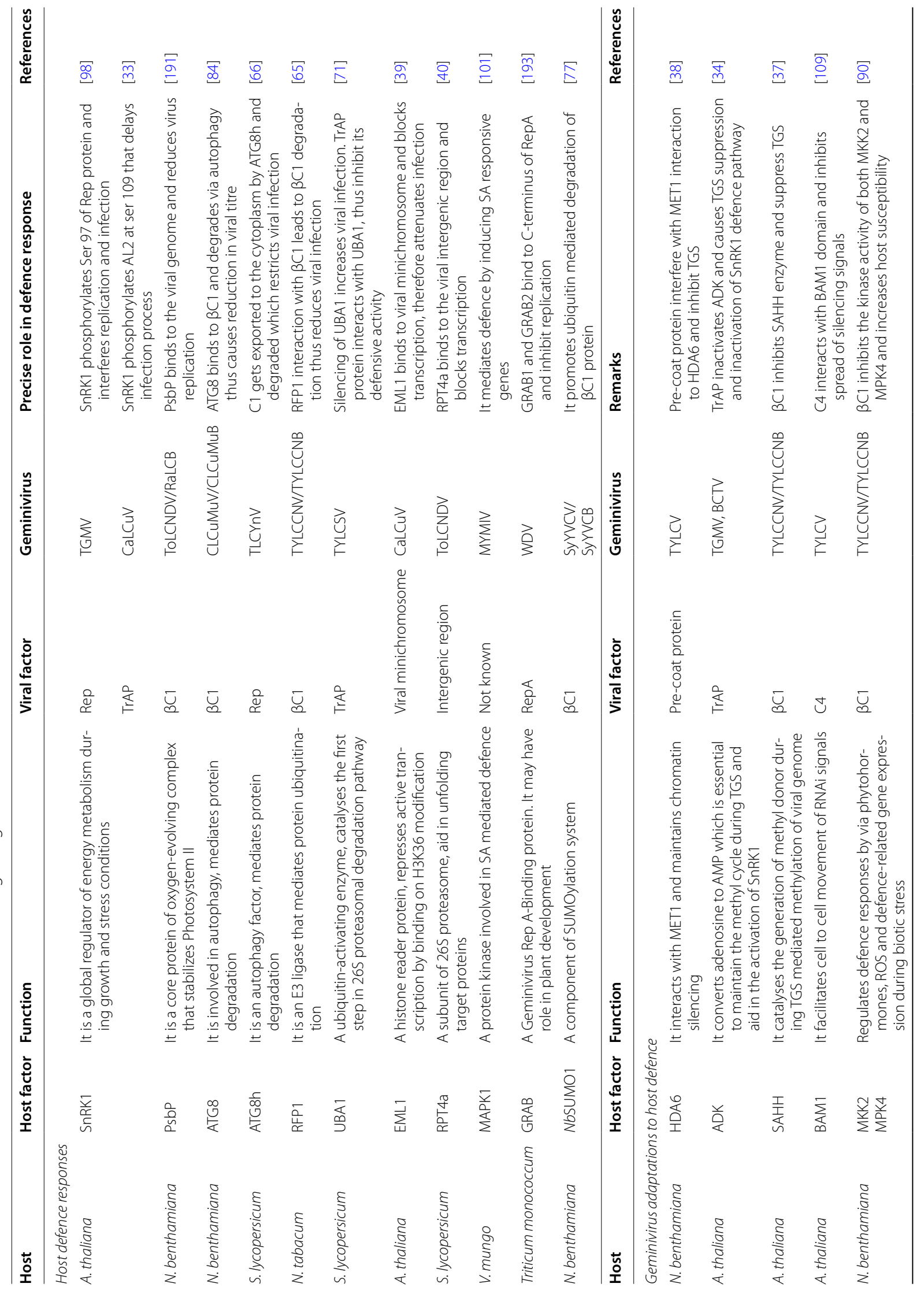




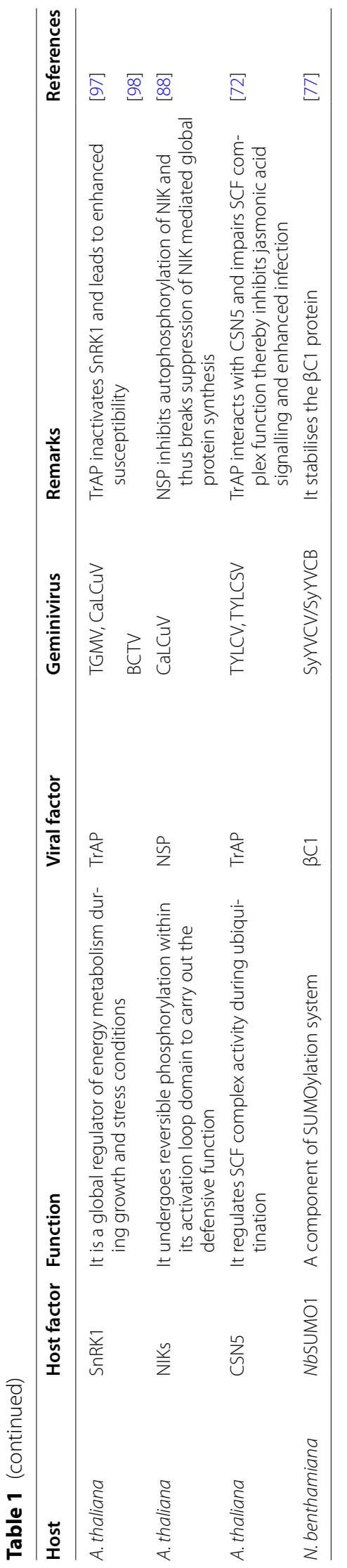




\section{Phytohormone modulations}

Phytohormones not only regulate various physiological activities related to development, metabolism, reproduction but they are also essential in management of abiotic and biotic stresses [130, 131]. Various phytohormones like salicylic acid (SA), jasmonic acid (JA), and ethylene have been known to work either synergistically or antagonistically to generate diverse host defence responses against pathogens. Crucial roles of JA, SA against geminiviruses have been elucidated and the involvement of auxin, cytokinin, gibberellic acid, brassinosteroids and abscisic acid in the anti-virus activity are being explored [132].

SA is synthesized in plants during biotic stress and establishes both local and systemic acquired resistance (SAR) via synthesis of PR proteins. CaLCuV infected $A$. thaliana transcriptome analysis revealed activation of the SA pathway during infection as Arabidopsis cpr1 plants that exhibited high endogenous SA level and increased PR proteins expression were less susceptible to CaLCuV infection [133]. Similarly, overexpression of GLUTAMINE DUMPER 3 (LSB1/GDU3), a gene important in amino acid transport, activates the SA pathway and weakens DNA replication of BSCTV [134]. However, during TYLCSV infection in S. lycopersicum, biosynthesis of SA has been reported to be reduced. SA minimises the egg hatchability of vector whitefly putting pressure on viral propagation [135]. Recent report suggests induction of expression of SA responsive PR genes (SIPR1, SlPR2, and SlPR5) and ROS scavenging enzymes (SlSOD, SlPOD, SlCAT2) following TYLCV infection in S. lycopersicum which contributes to increased resistance against the virus [136].

Methyl jasmonate (MeJA) treated plants also developed milder symptoms and low viral titre compared to the control plants when infected with BCTV [86]. Tomato plants infected with TYLCSV had several JA responsive genes upregulated including JA signaling pathway gene COI1 but had the lower level of JASMONATE INSENSITIVE1 (JAI1), a transcription factor activated by the JA [67]. $N$. tabacum transgenic plants expressing TrAP protein had increased expression of JA biosynthetic genes as well. Although betasatellite encoded $\beta C 1$ protein did not have a direct impact on JA biosynthetic genes, it represses JA downstream marker genes such as PLANT DEFENSIN1.2 (PDF1.2), PATHOGENESIS RELATED4 (PR4) and CORONATINE INSENSITIVE13 (CORI3), thus hampering the hormonal defence suppression mechanisms [137]. As $\beta C 1$ interacts with $\mathrm{MYC} 2$, the MYC2-mediated JA responses gets suppressed [138]. Activation of JA leads to reduced development of whitefly $B$. tabaci nymphaea; however, the adult population can suppress JA related defence [139].
Gibberellic acid (GA) signalling is mediated via the degradation of DELLA proteins, which are negative growth regulators. GA biosynthesis and GA receptors genes were found to be upregulated in tomato plants infected with TYLCSV while the repressor protein of GA, Gibberellic-Acid Insensitive (GAI) downregulates, suggesting the fine tuning of GA homeostasis during the geminiviral infection [67]. CLCuMuB $\beta C 1$, when interacts with the DELLA protein, represses its degradation, affecting the GA response pathway.

Role of classic growth hormones like auxins and cytokinins against geminiviruses are yet to be explored conclusively. Auxin is a pivotal regulator of growth and development of stem and roots as responsiveness to light and temperature. Through its precursor Tryptophan, auxin signalling is related to chemical defence pathways involving camalexins and glucosinolates that selectively inhibits the growth of necrotrophic and biotrophic pathogens [140]. ToLCNDV-encoded AC4 disrupts endogenous auxin content and downstream signaling cascade in tomato by interacting with auxin biosynthetic enzymes such as TAR1 (tryptophan amino transferase 1)-like protein, CYP450 monooxygenase. It also upregulates the expressions of miRNAs that target auxin signaling components, reprogramming the virus replication and altering the symptom manifestation [141]. RNA sequence analysis of WDV infected samples showed downregulation of auxin-induced protein 15A and auxin-responsive protein SAUR72 compared to the control plants. Small auxin upregulated RNA (SAUR) family proteins are involved in the Auxin/Indole-3-acetic acid (AUX) signalling pathway. The downregulation of SAUR72 suggested the possible roles of auxins in antiviral response. Similarly, two-component response regulator encoding ORR22 and ORR4 genes that are involved in cytokinin signalling pathways were upregulated and downregulated, respectively [142]. TGMV TrAP protein and spinach curly top virus (SCTV) C2-encoded TrAP protein expression resulted in inhibition of activity of ADK, a regulator of primary cytokinin responsive genes. Inhibition of ADK prevents cytokinin nucleosides phosphorylation leading to the accumulation of more bioactive cytokinins [143]. This increases the cell division rate and promotes severe infection. Regulation of level of cytokinins may decisively control the susceptibility of plants towards geminiviruses.

Abscisic acid is a widely studied phytohormone in plant abiotic stress tolerance. However, the correlation between geminivirus infection and abscisic acid has largely remained unexplored. Exogenous application of abscisic acid and auxin induces expression of $A$. thaliana homeobox ATHB7 and ATHB12 genes that encode homeodomain-leucine zipper family transcription 
factors. Similar genes were found to be induced during BSCTV infection [67]. Since expression of ATHB12 in BSCTV infected plants leads to several abnormalities like stunting, curling of leaves, abnormal floral and root structure, callous like outgrowths in plants, this indicates a regulation of geminiviral response by abscisic acid [144]. ABA is known to enhance the survival capability of plants in drought conditions. Recently, an interesting finding described enhanced drought tolerance capacity of transgenic A. thaliana plants expressing TYLCV C4 protein [131]. However, this alteration of the physiological aspect of infected plants is through ABA independent mechanism.

Ethylene (ET) is another plant hormone that is involved in defence mechanism. The level of 1-aminocyclopropane-1-carboxylate oxidase (ACCO), a vital molecule of ethylene biosynthesis pathway, is increased during TYL$\mathrm{CSV}$ and CaLCV infection. However, 1-aminocyclopropane-1-carboxylate synthase 8 (ACS8) that catalyses the rate-limiting step in the biosynthetic pathway of ethylene is downregulated during TYLCSV infection [67]. The level of ACS8 targeting miR159 increases along with the disease progression, reducing the level of 1-aminocyclopropane-1 carboxylic acid (ACC), another ethylene precursor, which is probably compensated by the upregulation of ACCO. A dynamic equilibrium involving ET signalling plays at the interface of host and virus interaction [67]. Ethylene responsive factor 1 (ERF1) gene, the regulator of ethylene-responsive genes was also upregulated when ACMV TrAP protein was overexpressed in N. tabacum [145]. Likewise, the systemic silencing of CONSTITUTIVE TRIPLE RESPONSE 1 (CTR1), a negative regulator of ET signaling enhances upregulation of defence marker genes during tomato leaf curl Joydebpur virus (ToLCJoV) infection [146]. Suppressed expression of essential ET responsive EIN2 in case of WDV infecting a monocot plant might underline the evolutionary diversification of the plants [142].

BCTV C4 protein induces severe development abnormalities like hyperplasia of phloem tissue and tumourlike outgrowths in infected plants, and conversely, a mutation in $\mathrm{C} 4$ causes reduction in disease symptoms [147]. When brassinosteroids and abscisic acid were applied exogenously, the C4 transgene-induced phenotype of seedlings was partially rescued. However, seedlings became more sensitive to gibberellic acid and kinetin [148]. An earlier report revealed that Arabidopsis Shaggy-like kinase proteins (AtSKs), which targets transcription factors that regulate brassinosteroid signalling also interact with the C4 protein of BCTV and TGMV [149]. Current transcriptomic studies in response to the WDV in Triticum aestivum showed differential expression of BR signalling genes [142]. Different classic and stress-responsive phytohormones act in concert in the plants' immunity and it is important to decipher the roles of these hormones in this complex network.

\section{Metabolite interplay}

Plants varied responses against biotic stresses are often associated with the production of a variety of metabolites. Beet mild curly top virus (BMCTV) infection on chilli pepper induces a high level of glucose and fructose, galactose, and myoinositol compared to asymptomatic samples [150]. Glucose and fructose act as energy sources for running viral machinery, while galactose may be required for the synthesis of the glycoprotein required for capsid formation [151]. As an osmoregulator, myoinositol is also involved in tissue deformation during ageratum enation virus (AEV) infection [152]. In chilli, geminivirus infection induces prominent symptoms of leaf curling, yellowing, etc., and reduces the total chlorophyll $\mathrm{a}$ and $\mathrm{b}$ content affecting the $\mathrm{CO}_{2}$ fixation rate and total soluble sugars, proteins and starch content $[6$, 153-155]. TYLCV infection increases total phenolics, tannins, and the related gene expression but reduces the soluble sugars and free amino acids that impacts the growth and fecundity of whitefly [156]. Alteration of nutritional changes brought about by geminiviruses favour the abundance, fecundity, and transmission ability of vector whitefly to promote the spread of the virus. Various volatile organic substances released from secretory organs such as glandular trichomes, secretory cavities, and resin ducts, specifically acts as an attractant or repellent to specific herbivores and insect vectors. A fatty acid derivative undecanone, sesquiterpene zingiberene, and its transformed form, curcumene produced from tomato plants are reported to be toxic to whitefly [157]. Resistance towards one of the whitefly species was observed when zingiberene containing ginger oil was applied on the leaves of the tomato plant [158]. P-cymene, one of the active and toxic volatile substances may also play a role in repelling whitefly [157]. The infestation of whitefly leads to the upregulation of terpenoid biosynthesis genes. This secondary metabolite mediated defence is compromised by viral infection as the virus attenuates the terpenoid release. The number of whiteflies in different development stages were also higher in plants with silenced 5-epi-aristolochene synthase (EAS) gene, a terpenoid synthesis gene in tobacco [159]. $\beta C 1$ protein encoded from TYLCCNB associated with TYLCCNV inhibits terpene synthesis by interacting with MYC2 transcription factor [138]. Utilizing the chemistry of secondary metabolites in controlling the herbivory can be an easy and time-efficient approach in managing the whitefly populations in field conditions. 


\section{Innate genetic factors and hypersensitive response mediated responses}

Disease resistance to phytopathogens is classified into nonhost resistance and host resistance. In the context of viral pathogenesis, nonhost resistance is a speciesdependent phenomenon where the genotypes belonging to particular plant species might exhibit resistance or susceptibility to a specific virus [160]. While in the case of host resistance, it is typically limited to specific genotypes or cultivars of same or different species and renders the rest of them to be susceptible to the virus infection. There are multiple genetic studies describing the disease resistance phenotype is explicitly associated with occurrence of gene loci encode for resistance $(R)$ genes. In the dynamic population, R-genes segregate into dominant and recessive. Often it is found that the former exerts defence responses mostly by induction of HR response [161] and the latter inhibits the virus life cycle by impeding the protein translation [162]. Identification of promising resistant genetic sources from domestic and wild varieties has been a longstanding successful approach in managing the geminiviruses against several crops such as tomato, bhendi, cassava, cotton and mung bean [163].

Frequent occurrence of TYLCV epidemics in tomato cultivating regions has posited the tomato infecting geminivirus such as TYLCV as a potential threat for the production. Genetic approaches to gain tolerance/resistance to TYLCV resulted in the mapping of six resistance Ty- loci, i.e. Ty 1-6 from different wild tomato species and, except for $T y-4$ and $T y-6$, rest of the $T y$ genes have been characterized (Table 1). Ty genes confer phenotypic disease tolerance to begomoviruses, but unlike the reported R-genes, doesn't induce HR. Tomato varieties possessing Ty-1/Ty-3 alleles upon infection with TYLCV produced mild or no symptoms with low virus titre, but an increased accumulation of siRNAs. Ty- 1 and Ty-3 are allelic forms of $\Upsilon$ type of RNA dependent RNA polymerase gene (RDRT) [164]. As increased siRNAs production derived from V1 and C3 genes, enhanced TGS conferred Ty-1 mediated resistance in TYLCV infected plants where hypermethylation of cytosine residues in the V1 and $\mathrm{C} 3$ promoters of tomato severe rugose virus (ToSRV) were observed [165]. However, the resistance mediated by $T y-1$ against TYLCV was compromised by mixed infection with cucumber mosaic virus (CMV). CMV encodes silencing suppressor proteins which counteract the host RNAi machinery and trade-off TYLCV resistance in plants and enhances the viral titre and infection severity [165]. Ty-1/Ty-3 have been found to be essential for achieving broad-range resistance against geminiviruses as they provide a high degree of resistance to both mono and bipartite begomoviruses [166]. Ty-2 is a functional $\mathrm{R}$ gene that encodes for nucleotide-binding-leucine rich repeat protein. The insertion of $T y-2$ gene into the domestic susceptible tomato plants conferred resistance to TYLCV [167]. Quantitative trait locus, Ty-5 majorly has also been implicated in recessive resistance against TYLCV in TY172 line of tomato [168]. At this locus, Pelo gene which encodes for mRNA surveillance factor pelota (pelo) homolog in tomato, is involved in ribosome recycling phase of protein biosynthesis and controls the disease resistance [162]. Experimental evidence suggests that Pelo silenced susceptible transgenic plants infected with TYLCV failed to produce disease symptoms, and viral titre was decreased by $20-60$-fold. The possible mechanism might involve affected ribosome dissociation, leading to low availability of ribosomal subunits for translation initiation of viral proteins [162]. Ty-4 and Ty-6 also provide resistance against TYLCV and tomato mottle virus (ToMV) [169, 170]. Apart from exploiting $T y$ loci in breeding, devising the molecular biology tools may provide an opportunity for developing broad resistance against plant viruses. However, the resistance conferred by Ty genes can be compromised by the presence of betasatellite during the infection [171]. Breeding approaches also have identified inter simple sequence repeat (ISSR), a key diagnostic marker, in ToLCNDV tolerant cultivar Solanum habrochaites LA1777 which can be exploited for marker-assisted breeding in rising defence against ToLCNDV. Two genetic markers SSR1 $_{170-145}$ and SSR304 ${ }_{158-186}$ have been identified from the F2 population of susceptible variety Punjab Chhuhara (PBC), 'H-24', and S. habrochaites accession 'EC-520061' with possible implications in TYLCV resistance [172].

Three resistance genes CMD1, CMD2 and CMD3 have been identified against cassava mosaic geminiviruses that are prevalent in South Africa and India. CMD1 is a polygenic resistance gene originally from Manihot glaziovii [173]. Several CMD resistant varieties were obtained utilizing CMD1 through breeding that exhibited lower viral titre than the susceptible ones and had reduced systemic movement of virus enabling to develop virus-free plants from infected cuttings [174]. Molecular genetic mapping and analysis have led to the identification of CMD2, a monogenic dominant locus from $M$. esculenta. Crossing CMD1 and CMD2 carrying parents, that together produce complementary resistant effect, have generated CMD3, another quantitative trait loci responsible for resistance in cassava [175]. Although several breeding programs successfully obtained CMD resistant varieties, molecular characterization of these genes has not yet progressed much. As geminiviruses can evolve into more virulent strains and break the natural resistance provided by marker-assisted selection and breeding, it is important to develop resistance against virus by additional genetic engineering methods. 
Because of its high-quality fibre and superior lint $G$. hirsutum accounts for more than $90 \%$ of total cotton production all over the world. But it is highly susceptible to cotton leaf curl disease (CuLCD) caused by Cotton leaf curl virus [176]. G. arboreum, one of the wild progenitors of G. hirsutum, has been highly tolerant to various biotic and abiotic stresses and a major source of genes for natural resistance. Through introgression and conventional hybridization programs, single genes with dominant effect for resistance were transferred from G. arboreum to G. hirsutum [177]. Massive screening of 22 cotton varieties revealed two genes $R_{1 C L C u D h i r}$ and $R_{2 C L C u D h i r}$ that were involved in G. hirsutum resistance and one gene $\mathrm{S}_{\mathrm{CLCuDhir}}$ as suppressor of resistance [178]. However, introgression of multiple genes for resistance with minor effects can provide plants with durable resistance [179].

Bhendi (Abelmoschus esculentus) is an important vegetable crop in the tropical and subtropical countries of Indian subcontinent is greatly challenged by bhendi yellow vein mosaic virus (BYVMV) and okra enation leaf curl virus (OELCV). Various bhendi resistant varieties have been developed through conventional breeding experiments in the past 50 years. The responsible factors of natural resistance transferred during the breeding were either two recessive genes or two complementary dominant genes [180-184]. Presence of a single dominant gene or two dominant genes may also provide resistance against the virus [185-187] (Table 2). Various molecular markers RAPD, SSR, AFLP, have been seemingly associated with the resistant genes identified which may assist in characterizing resistance genes.

Responsible for a yield loss of up to $100 \%$, Bean golden mosaic virus is one of the major concerns for common bean (Phaseolus vulgaris) production. Resistant recessive genes, $b g m-1$ and $b g m-2$ were identified from a highly disease-resistant variety of bean from Mexico $[188,189]$. Later on, several durable breeding lines were developed utilizing these resistance genes. Another $\mathrm{R}$ gene from Phaseolus vulgaris cultivar Othello, named PvVTT1 (Phaseolus vulgaris VIRUS response TIR-TIR GENE 1) found to be responsible for resistance against bean dwarf mosaic virus (BDMV) through HR mediated defence response [161]. The dominant resistance gene Bgp-1 has also been reported to account for normal pod development during viral infection and involve in providing resistance against BGYMV [190]. Similarly, bean leaf crumple disease of $P$. vulgaris is associated with TYLCV and is controlled by the dominant gene PvBlc [191]. Phaseolus also has resistance gene $B c t-1$, linked to the RAPD marker against BCTV [192]. In addition, the expansion of genetic studies on cucurbits against ToLCNDV infection revealed the occurrence of a single dominant resistance gene in Luffa cylindrica (Roem.) [193, 194]. Three candidate genes [195] and recently, one major quantitative trait locus (QTL) on chromosome 8 conferring resistance to ToLCNDV have been found in melon [196].

Natural hybridization and conventional breeding programs have utilized the natural resistance resources of plant genomes to combat virus infection via introgression for successful management of plant viruses. However, to attain stable resistance, it is important to further analyse and characterize these genetic sources and implementation of advanced speed breeding techniques for advanced phenotyping and quick transformation outputs. Although findings are promising in controlling the geminiviruses, resistance breakdown occurs frequently requiring continuous exploration of new resistance sources among geminivirus infecting crops. As geminiviruses have been observed in association with nanovirus, potyvirus, and other plant RNA viruses, investigation of commonly conserved genetic factors among the phytopathogens is crucial for tackling the mixed infections in regular filed conditions [197]. For instance, the phenomenon of single R-gene controls the unrelated pathogen clusters. Wheat $B d v 1$ locus shows resistance to barley yellow dwarf virus (BYDV) also interfere R-genes of fungal pathogens, causing leaf rust [198].

Plant immune system has evolved multi-layer receptor systems to sense and induce the pathogen defence responses. The first layer of defence employs the cell surface radars known as pathogen recognition receptors (PRR) that recognise extracellular immune targets called pathogen associated molecular patterns (PAMPs). However, to circumvent this basal defence, pathogens employ sophisticated intracellular immune suppressors called effectors (Avr) which in turn are intercepted by the host resistance (R) genes, that encode for NBSLRR type receptors, leading to rapid immune responses called effector-triggered immunity (ETI) [199]. These $\mathrm{R}$-genes sense the effectors via direct or indirect interactions to initiate physiological and biochemical defence responses such as reactive oxygen species (ROS) generation, cell wall fortification, defence gene expression and HR at the infection site followed by induced SAR, at the distant leaves to restrict the pathogen growth and systemic movement [199]. Bean dwarf mosaic virus (BDMV)-NSP elicits HR response in BDMV resistant bean cultivar Pinto bean cvs. Othello [200]. Similarly, Rep protein of ACMV and TYLCV, pre-coat protein of tomato leaf curl Java virus (ToLCJV), and TrAP of TYLCSV also induce HR, so also does the recently identified a novel TYLCCNB $\beta V 1$ gene [19, 201-203]. Often, overexpression of individual geminiviral ORFs induces visible HR or necrotic symptoms, which do not appear during virus infection, suggesting the geminiviruses also encode for proteins that mediate HR suppression. AC4 


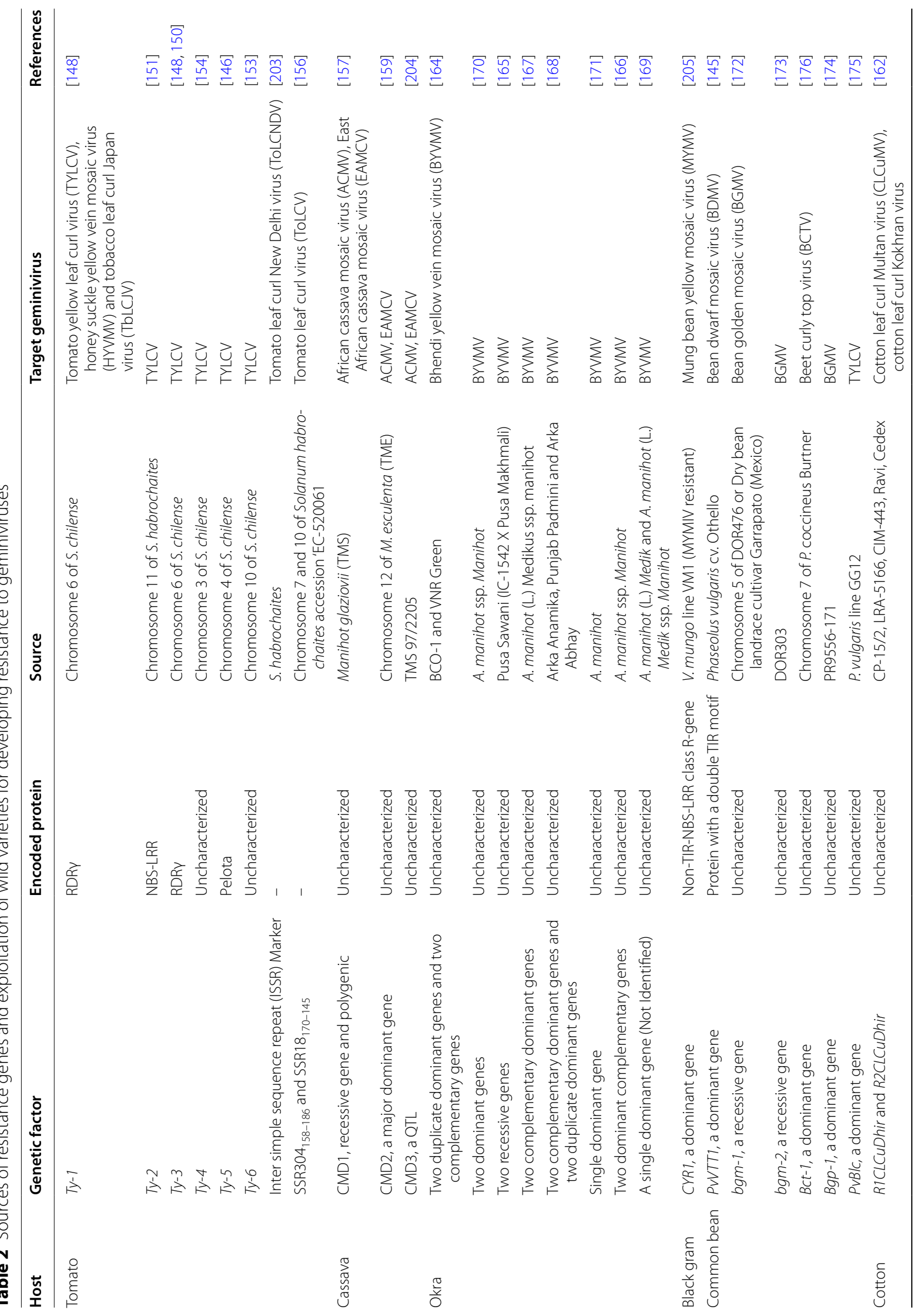




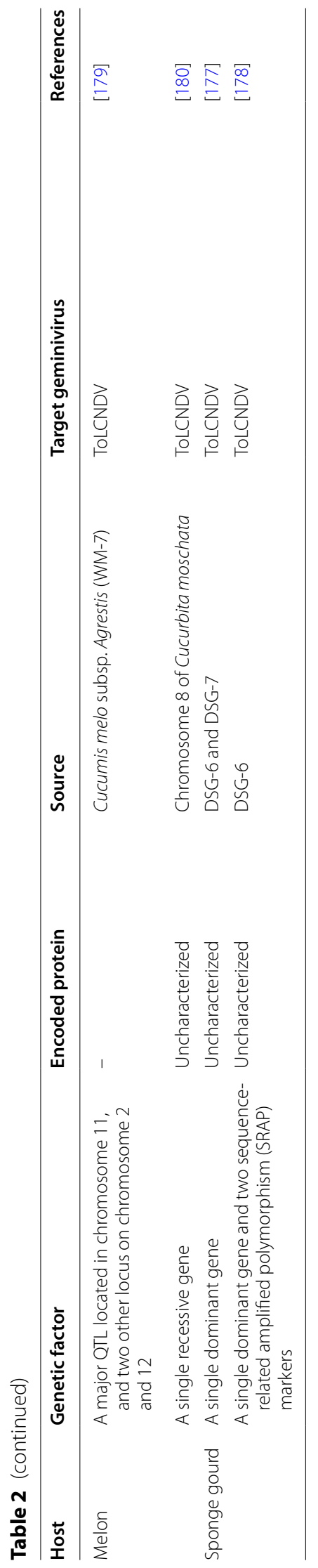


protein of ACMV may negatively affect the Rep mediated HR responses to promote virulence [201] while TLCYnV encoded C4 physically interacts with HIR1 (hypersensitive induced reaction 1) and perturbs the HIR1 homodimerisation to counteract HIR mediated HR response [204]. Due to limited coding capacity, unlike other plant pathogens, viruses do not strictly fit into the Gene-forGene theory of host-pathogen interactions. However, to overcome the limitation, viruses have evolved multifunctional proteins that maintain a coevolutionary relationship with the host to invade the host defence machinery.

\section{Other cellular factors}

The chloroplast is a hub of plant's immune arsenal, not only by producing immune signals such as ROS and SA but also to initiate the biosynthesis pathways of the phytohormones GA, ABA and JA that are crucial for biotic and abiotic stress tolerance [205]. Hence, to suppress the active host defence, viruses primarily target the chloroplast machinery to attain successful infection [206]. Radish leaf curl betasatellite ( $\mathrm{RaLCB}$ ) encoded $\beta \mathrm{C} 1$ protein disturbs chloroplast organization, photosynthetic efficiency and causes veinal chlorosis [6]. A recent finding suggests PsbP (photosystem II subunit P), an extrinsic protein of oxygen-evolving complex (OEC), plays a defensive role against geminiviruses [207]. PsbP-silenced plants, had higher virus titre than the control plants and $P s b P$ overexpression lines showed reduced disease symptoms evidenced by lower virus replication at early stages of infection. However, during later phases of infection, RaLCB- $\beta C 1$ interacts with PsbP and permits successful virus replication [207]. Host regulatory proteins such as GRAB (Geminivirus Rep-A binding) proteins of NAC transcription factor families, that are involved in leaf development and senescence, can be modulated to interacting with viral proteins such as RepA to facilitate viral replication or suppress host immunity [208]. Interaction with GRAB protein has been shown to inhibit WDV infection, but enhance TYLCSV infection [209]. Overexpression of Arabidopsis TIFY4B, a plant DNA binding protein, responsible for cell cycle arrest, causes a reduction in viral titre and increase the latent period for symptom production. Increased expression of TIFY4B after geminiviral infection also suggests its crucial role in defence against the viruses. Furthermore, to hinder the plant defence response, TrAP protein encoded by TGMV and $\mathrm{CaLCuV}$ interacts with TIFY4B to counteract the cell cycle arrest leading to increased viral load [210].

\section{CRISPR-Cas9 based resistance against geminivirus}

The application of advanced genetic engineering methods has helped to overcome the limitations of labourintensive traditional approaches for developing resistant plants. CRISPR-Cas (Clustered, regularly interspaced short palindromic repeats-CRISPR associated protein) is a bacterial adaptive immune strategy against invasive foreign nucleic acids, that has been exploited to target plant viruses. In this technique, single guide RNA (sgRNA) directs an endonuclease Cas9 to modify specified viral DNA targets by inducing double-stranded breaks which eventually leads to viral genome degradation. This technique has already been proved successful in reducing the viral titer and symptom expression against the monopartite and bipartite geminiviruses [211]. Transient expression of sgRNA-Cas9 directed to dsDNA intermediate forms of BSCTV has reduced the viral accumulation by $80 \%$ and abolished the disease symptoms in N. benthamiana plants [211]. The findings of Baltes et al. [212] corroborated the CRISPR system's efficiency against bean yellow dwarf virus (BeYDV)-eGFP by estimating the fluorescence intensity relative to the control plants. Systemic targeting of BeYDV key regulatory elements such as conserved nonanucleotide hairpin, rep binding sites (RBS), and Rep protein motifs that are crucial for replication has reduced the viral DNA accumulation [212]. Considering the sequence-specificity of the technique, targeting the conserved geminiviral IR region with a suitable a sgRNA (IR-sgRNA) can provide a universal approach to control geminivirus infections, even for the commonly occurring mixed infections in the field conditions. Systemic delivery of IR-sgRNA in $N$. benthamiana Cas9OE plants infected separately with TYLCV, BCTV, and merremia mosaic virus (MeMV) displayed symptom attenuation and suppression of viral DNA against infections [213]. Notwithstanding the promising CRISPR applications, CRISPR-induced virus evolution must be critically examined to monitor the emergence of resistant viruses [214]. Recently the breakdown of CRISPR resistance has been reported, where ACMV-AC2 evolved a conserved single " $\mathrm{T}$ " insertion that can affect the Cas9 target-cleavage activity [215]. Additionally, non-homologous end joining (NHEJ) repair of plant system is a posing threat that could repair the Cas 9 targeted viral dsDNA intermediates [213, 215]. Importantly recombination, a driving force of geminivirus evolution, which allows swapping of genomic sequences during mixed infections, also enables the geminiviruses to escape the CRISPR induced cleavage, subsequently leading to CRISPR resistance. 


\section{Conclusions}

Plants have evolved to develop very complex defence strategies against geminiviral infection. RNA silencing machinery remains to be one of the prominent mechanisms. While TGS carries out viral genome methylation, consequently, leads to the repression of viral pathogenicity proteins, PTGS mediates the degradation of the viral mRNAs, thereby inhibit the viral infection. Several chromatin remodelers have evolved in plants that carry out repressive modifications on host genome, diverts targeting viral genome. miRNAs have emerged as effective tools for achieving broad spectrum resistance against geminiviruses. Another level of defence against geminiviruses is mediated through $\mathrm{R}$-genes that are well studied in case of fungi and bacteria and in this context geminiviruses are highlighted recently. Several other host defence regulatory mechanisms like autophagy, ubiquitination, hormonal signalling, protein kinases also play a significant role in guarding and shielding the host from geminivirus by providing the ammunition to the host to act against geminivirus. Against these wide array of defence mechanisms, various suppressor proteins and evolved sophisticated strategies are deployed by the geminiviruses that emphasize the dynamic relationship between the host and the pathogens and unique role of geminiviruses in driving the co-evolution of both plants along with their own. Molecular studies carried out to elucidate the antiviral responses involve the characterization of potential targets in cellular transcriptome, proteome, metabolome in the background of geminivirus interaction. In the vast array of cellular pathways, identifying the mechanisms which does not influence the plant growth remains the principal task. Current efforts focus on the use of precise gene-editing tool for providing a broad range of resistance against viruses. Various laboratories worldwide are standardizing the CRISPR-cas9 system for providing broad range of adaptive immunity and resistance against geminiviruses. Selection of targets within viral genome is crucial factor in achieving the durable resistance. In this context, non-coding targets are more efficient over coding regions as they embed the crucial elements essential for virus replication and pathogenicity maintenance [216]. Incidences of geminiviral diseases are increasing at an accelerated pace due to high evolution rate expanding their geographical barrier and host range. Although, various techniques ranging from conventional methods to molecular approaches have been adopted to control the geminiviral infections, due to mixed virus infections the success is limited. Identifying the suitable host factors involved in the resistance during plant-geminivirus interaction, the introduction of multiplexed genetic engineering tools targeting multiple targets, and targeted deletion of large sequences from the viral genomes can aid in the development of disease-free plants and preventing the emergence of CRISPR resistant geminiviruses $[217,218]$.

\section{Abbreviations}

CR: Common region; REP: Replication-associated protein; TrAP: Transcription activator protein; REn: Replication enhancer protein; CP: Coat protein; MP: Movement protein; NSP: Nuclear shuttle protein; TGS: Transcriptional gene silencing; PTGS: Post-transcriptional gene silencing; HR: Hypersensitivity response; RDR2: RNA- DEPENDENT RNA POLYMERASE 2; CLSY1: CLASSY 1; DCL-3: DICER-LIKE 3; HEN1: HUA- ENHANCER 1; AGO4: ARGONAUTE 4; RISC: RNA-induced silencing complex; BCTV: Beet curly top virus; DDR complex: DEFECTIVE IN RNA DIRECTED DNA METHYLATION 1 (DRD1), DEFECTIVE IN MERISTEM SILENCING 3 (DMS3), REQUIRED FOR DNA METHYLATION 1 (RDM1) complex; NPRE1: Nuclear RNA polymerase E; KTF1: KOW DOMAIN-CONTAINING TRANSCRIPTION FACTOR 1; DRDM2: DOMAINS REARRANGED METHYL TRANSFERASE 2; SUVH4: SU(VAR)3-9 HOMOLOGUE 4; KYP: KRYPTONITE; CMT3: CHROMOMETHYLTRANSFERASE 3; RAV: RELATED TO ABI3 and VP1; DDM1:

Decrease in DNA methylation 1; Adk1: ADENOSINE KINASE 1; TYLCV:Tomato yellow leaf curl virus; BSCTV: Beet severe curly top virus; SAMDC1: S-adenosylmethionine decarboxylase; SAM: S-Adenosyl-methionine; dSAM: Decarboxylated SAM; SAHH: S-adenosyl homocysteine hydrolase; MET1: Methyltransferase 1; HDA6: Histone deacetylase 6; EML1: EMSY-LIKE 1; RPT4a: REGULATORY PARTICLE TRIPLE-A ATPASE 4A; ToLCNDV: Tomato leaf curl New Delhi virus; RDR1: RNA-dependent RNA polymerase 1; ToLCGV: Tomato leaf curl Gujarat virus; VMYMV: Vigna mungo yellow mosaic virus; DCL: DICER- LIKE protein; DRB: DsRNA binding proteins; AS2: ASYMMETRIC LEAVES 2; DCP2: DECAPPING 2; CaM: Calmodulin-like protein; SGS3: SUPPRESSOR OF GENE SILENCING 3; WDV: Wheat dwarf virus; CLCUMuB: Cotton leaf curl Multan betasatellite; TMV: Tobacco mosaic virus; ToLCV: Tomato leaf curl virus; MYMIV: Mung bean yellow mosaic India virus; MYMV: Mungbean yellow mosaic virus; CRLs: Cullin ring ligases; SCF complex: SKP1 (S phase kinase-associated protein 1)-CUL1(CULLIN 1)-F-box-protein; CSN: COP9 Signalosome; COI1: CORONATIN INSENSITIVE 1; JA: Jasmonic acid; JA-lle: Jasmonoyl isoleucine; JAZ: Jasmonate Zim domain; NtRFP1: Nicotiana tabacum RING FINGER PROTEIN 1; UBA1: Ubiquitin activating enzyme; UBC3: Ubiquitin-conjugating enzyme 3; CKIs: Cyclin-dependent kinase inhibitors; KPC: Kip-1 ubiquitination promoting complex; RKP1: Ring finger protein; UPS: Ubiquitin-proteasomal system; SCE1: SUMO CONJUGATING ENZYME 1A; TGMV: Tomato golden mosaic virus; TYLCSV: Tomato yellow leaf curl Sardinia virus; ACMV: African cassava mosaic virus; PCNA: Proliferating cell nuclear antigen; ATG8: AUTOPHAGY-RELATED 8; CLCUMuV: Cotton leaf curl Multan virus; TLCYnV: Tomato leaf curl Yunnan virus; TYLCCNB: Tomato yellow leaf curl China betasatellite; RLKs: Receptor like kinases; SnRK1: SUCROSE NONFERMENTING1 related protein kinase 1; CaLCuV: Cabbage leaf curl virus; GRIK1: Geminivirus Rep interacting kinase 1; AtREM4: Arabidopsis thaliana remorin group 4; ATP: Adenosine triphosphate; AMP: Adenosine monophosphate; MAPKs: Mitogen-activated protein kinase; SA: Salicylic acid; PR: Pathogenesisrelated; MKK2: Map kinase kinase 2; PRRs: Pattern recognition receptors; MAMPs: Microbe-associated molecular patterns; NIK: NSP interacting kinase; RPL10: Ribosomal protein 10; LIMYB: L10-interacting MYB domain-containing protein; CLV1: CLAVATA 1; BAM1: BARELY ANY MERISTEM 1; AtBIN2: Arabidopsis thaliana Brassinosteroid insensitive 2; SPLCV: Sweet potato leaf curl virus; FLS2: FLAGELLIN SENSING 2; BRI1: BRASSINOSTEROID INSENSITIVE 1; PERK: Proline-rich extension-like receptor kinase; TCrLYV: Tomato crinkle leaf yellows virus; PXYS: PHLOEM INTERCALATED WITH XYLEM members; PEPRs: PEP1 RECEPTOR members; GDU3: GLUTAMINE DUMPER 3; SOD: Superoxide dismutase; POD: Peroxidase; CAT: Catalase; MeJA: Methyl jasmonate; JAl1: JASMONATE INSENSITIVE 1; PDF1.2: PLANT DEFENSIN 1.2; CORI3: CORONATINE INSENSITIVE 13; GA: Gibberellic acid; GAl: Gibberellic-acid insensitive; SAUR: Small auxin upregulated RNA; AUX: Auxin/Indole-3-acetic acid; ORR22: Oryzae sativa response regulator; SCTV: Spinach curly top virus; ATHB7: Arabisopsis thaliana homeobox 7; ET: Ethylene; ACCO: 1-Aminocyclopropane-1-carboxylate oxidase; ACS8: 1-Aminocyclopropane-1-carboxylate synthase 8; ACC 
: 1-Aminocyclopropane-1 carboxylic acid; ERF1: Ethylene responsive factor 1; CTR1: CONSTITUTIVE TRIPLE RESPONSE 1; TOLCJOV: Tomato leaf curl Joydebpur virus; BMCTV: Beet mild curly top virus; AEV: Ageratum enation virus; EAS: 5-Epi-aristolochene synthase; RDR: RNA dependent RNA polymerase; ToSRV: Tomato severe rugose virus; CMV: Cucumber mosaic virus; ToMV: Tomato mottle virus; ISSR: Inter simple sequence repeat; CMD: Cassava mosaic disease; CuLCD: Cotton leaf curl disease; CuLCV: Cotton leaf curl virus; BYVMV: Bhendi yellow vein mosaic virus; OELCV: Okra enation leaf curl virus; RAPD: Random amplified polymorphic DNA; AFLP: Amplified fragment length polymorphism; BGMV: Bean golden mosaic virus; BDMV: Bean dwarf mosaic virus; BYDV: Barley yellow dwarf virus; NBS-LRR: Nucleotide-binding site and leucine-rich repeat; ETI: Effector-triggered immunity; SAR: Systemic acquired resistance; ToLCJV: Tomato leaf curl Java virus; HIR1: Hypersensitive induced reaction 1; RaLCB: Radish leaf curl betasatellite; PsbP: Photosystem II subunit P; OEC: Oxygenevolving complex; GRAB: Geminivirus Rep-A binding; CRISPR-cas9: Clustered regularly interspaced short palindromic repeats and CRISPR-associated protein 9; NHEJ: Non-homologous end joining.

\section{Acknowledgements}

Not applicable.

\section{Authors' contributions}

$N G$, KR and SC organised the content; NG and KR wrote the first draft of the manuscript, NG, KR, DB and SC edited the manuscript; SC arranged the funding. All authors read and approved the final manuscript.

\section{Funding}

This work was supported by a grant from the Department of Biotechnology, Govt of India vide Grant No. BT/PR31648/GET/119/283/2019 to SC. NG is supported by Council of Scientific training and Industrial Research (CSIR) fellowship.

\section{Availability of data and materials \\ Not applicable.}

\section{Declarations}

\section{Ethics approval and consent to participate}

Not applicable.

\section{Consent for publication}

Not applicable.

\section{Competing interests}

The authors declare that they have no competing interests.

Received: 15 April 2021 Accepted: 29 June 2021

Published online: 09 July 2021

\section{References}

1. Jeske H, Lütgemeier M, Preiss W. DNA forms indicate rolling circle and recombination-dependent replication of Abutilon mosaic virus. Embo J. 2001;20(21):6158-67.

2. Hanley-Bowdoin L, Bejarano ER, Robertson D, Mansoor S. Geminiviruses: masters at redirecting and reprogramming plant processes. Nat Rev Microbiol. 2013;11(11):777-88.

3. Abouzid AM, Frischmuth T, Jeske H. A putative replicative form of the abutilon mosaic virus (gemini group) in a chromatin-like structure. Mol Gen Genet MGG. 1988;212(2):252-8.

4. Kushwaha NK, Mansi B, Chakraborty S. The replication initiator protein of a geminivirus interacts with host monoubiquitination machinery and stimulates transcription of the viral genome. PLoS Pathog 2017;13(8):e1006587.

5. Mansoor S, Zafar Y, Briddon RW. Geminivirus disease complexes: the threat is spreading. Trends Plant Sci. 2006;1 1(5):209-12.

6. Bhattacharyya D, Gnanasekaran P, Kumar RK, Kushwaha NK, Sharma VK, Yusuf MA, et al. A geminivirus betasatellite damages the structural and functional integrity of chloroplasts leading to symptom formation and inhibition of photosynthesis. J Exp Bot. 2015;66(19):5881-95.

7. Zerbini FM, Briddon RW, Idris A, Martin DP, Moriones E, Navas-Castillo J, et al. ICTV virus taxonomy profile: geminiviridae. J Gen Virol. 2017:98(2):131-3.

8. Nawaz-ul-Rehman MS, Fauquet CM. Evolution of geminiviruses and their satellites. FEBS Lett. 2009;583(12):1825-32.

9. Fondong VN. Geminivirus protein structure and function. Mol Plant Pathol. 2013;14(6):635-49.

10. Kumar RV. Plant antiviral immunity against geminiviruses and viral counter-defense for survival. Front Microbiol. 2019;10:1460.

11. Ruhel R, Chakraborty S. Multifunctional roles of geminivirus encoded replication initiator protein. Virusdisease. 2019;30(1):66-73.

12. Lozano G, Trenado HP, Fiallo-Olivé E, Chirinos D, Geraud-Pouey F, Briddon RW, et al. Characterization of non-coding DNA satellites associated with sweepoviruses (Genus Begomovirus, Geminiviridae)—definition of a distinct class of begomovirus-associated satellites. Front Microbiol. 2016;7:162.

13. Gnanasekaran $P$, Chakraborty S. Biology of viral satellites and their role in pathogenesis. Curr Opin Virol. 2018;33:96-105.

14. Saunders K, Briddon RW, Stanley J. Replication promiscuity of DNAbeta satellites associated with monopartite begomoviruses; deletion mutagenesis of the Ageratum yellow vein virus DNA-beta satellite localizes sequences involved in replication. J Gen Virol. 2008;89(Pt 12):3165-72.

15. Saunders K, Stanley J. A nanovirus-like DNA component associated with yellow vein disease of Ageratum conyzoides: evidence for interfamilial recombination between plant DNA viruses. Virology. 1999;264(1):142-52.

16. Kumar J, Kumar J, Singh SP, Tuli R. $\beta C 1$ is a pathogenicity determinant: not only for begomoviruses but also for a mastrevirus. Arch Virol. 2014;159(11):3071-6.

17. Gnanasekaran P, KishoreKumar R, Bhattacharyya D, Vinoth Kumar R, Chakraborty S. Multifaceted role of geminivirus associated betasatellite in pathogenesis. Mol Plant Pathol. 2019;20(7):1019-33.

18. Saeed M, Behjatnia SA, Mansoor S, Zafar Y, Hasnain S, Rezaian MA. A single complementary-sense transcript of a geminiviral DNA beta satellite is determinant of pathogenicity. Mol Plant Microbe Interact. 2005;18(1):7-14.

19. Hu T, Song $Y$, Wang $Y$, Zhou $X$. Functional analysis of a novel $\beta V 1$ gene identified in a geminivirus betasatellite. Sci China Life Sci. 2020;63(5):688-96.

20. Briddon RW, Bull SE, Amin I, Idris AM, Mansoor S, Bedford ID, et al. Diversity of DNA beta, a satellite molecule associated with some monopartite begomoviruses. Virology. 2003;312(1):106-21.

21. Reddy K, Bhattacharyya D, Chakraborty S. Mutational study of radish leaf curl betasatellite to understand the role of the non-coding region in begomovirus pathogenesis. Physiol Mol Plant Pathol. 2020;112:101549.

22. Vanitharani R, Chellappan P, Fauquet CM. Geminiviruses and RNA silencing. Trends Plant Sci. 2005;10(3):144-51.

23. Zarreen F, Chakraborty S. Epigenetic regulation of geminivirus pathogenesis: a case of relentless recalibration of defence responses in plants. J Exp Bot. 2020;71(22):6890-906.

24. Ceniceros-Ojeda EA, Rodríguez-Negrete EA, Rivera-Bustamante RF. Two populations of viral minichromosomes are present in a geminivirus-infected plant showing symptom remission (recovery). J Virol. 2016;90(8):3828-38.

25. Ream TS, Haag JR, Wierzbicki AT, Nicora CD, Norbeck AD, Zhu JK, et al. Subunit compositions of the RNA-silencing enzymes Pol IV and Pol V reveal their origins as specialized forms of RNA polymerase II. Mol Cell. 2009;33(2):192-203.

26. Jackel JN, Storer JM, Coursey T, Bisaro DM. Arabidopsis RNA polymerases IV and $V$ are required to establish $\mathrm{H} 3 \mathrm{~K} 9$ methylation, but not cytosine methylation, on geminivirus chromatin. J Virol. 2016;90(16):7529-40.

27. Xie Z, Johansen LK, Gustafson AM, Kasschau KD, Lellis AD, Zilberman D, et al. Genetic and functional diversification of small RNA pathways in plants. PLoS Biol. 2004;2(5):E104. 
28. He XJ, Hsu YF, Zhu S, Wierzbicki AT, Pontes O, Pikaard CS, et al. An effector of RNA-directed DNA methylation in arabidopsis is an ARGONAUTE 4- and RNA-binding protein. Cell. 2009;137(3):498-508.

29. Haag JR, Pikaard CS. Multisubunit RNA polymerases IV and V: purveyors of non-coding RNA for plant gene silencing. Nat Rev Mol Cell Biol. 2011;12(8):483-92.

30. Sun YW, Tee CS, Ma YH, Wang G, Yao XM, Ye J. Attenuation of histone methyltransferase KRYPTONITE-mediated transcriptional gene silencing by geminivirus. Sci Rep. 2015;5:16476.

31. Deleris A, Halter T, Navarro L. DNA methylation and demethylation in plant immunity. Annu Rev Phytopathol. 2016;54:579-603.

32. Raja P, Sanville BC, Buchmann RC, Bisaro DM. Viral genome methylation as an epigenetic defense against geminiviruses. J Virol. 2008:82(18):8997-9007.

33. Shen W, Dallas MB, Goshe MB, Hanley-Bowdoin L. SnRK1 phosphorylation of AL2 delays Cabbage leaf curl virus infection in Arabidopsis. J Virol. 2014;88(18):10598-612.

34. Wang H, Hao L, Shung CY, Sunter G, Bisaro DM. Adenosine kinase is inactivated by geminivirus AL2 and L2 proteins. Plant Cell. 2003;15(12):3020-32.

35. Wang B, Li F, Huang C, Yang X, Qian Y, Xie Y, et al. V2 of tomato yellow leaf curl virus can suppress methylation-mediated transcriptional gene silencing in plants. J Gen Virol. 2014;95(Pt 1):225-30.

36. Wang L, Ding Y, He L, Zhang G, Zhu JK, Lozano-Duran R. A virusencoded protein suppresses methylation of the viral genome through its interaction with AGO4 in the Cajal body. Elife. 2020;9:e55542.

37. Wang Y, Wu Y, Gong Q, Ismayil A, Yuan Y, Lian B, et al. Geminiviral V2 Protein Suppresses Transcriptional Gene Silencing through Interaction with AGO4. JVirol. 2019;93(6):e01675-e1718.

38. Mei Y, Wang Y, Li F, Zhou X. The C4 protein encoded by tomato leaf curl Yunnan virus reverses transcriptional gene silencing by interact ing with NbDRM2 and impairing its DNA-binding ability. PLoS Pathog. 2020;16(10):e1008829.

39. Zhang Z, Chen H, Huang X, Xia R, Zhao Q, Lai J, et al. BSCTV C2 attenuates the degradation of SAMDC1 to suppress DNA methylation-mediated gene silencing in Arabidopsis. Plant Cell. 2011;23(1):273-88.

40. Yang X, Xie Y, Raja P, Li S, Wolf JN, Shen Q, et al. Suppression of methylation-mediated transcriptional gene silencing by $\beta C 1-S A H H$ protein interaction during geminivirus-betasatellite infection. PLoS Pathog. 2011;7(10):e1002329.

41. Wang $B$, Yang $X$, Wang $Y, X i e Y$, Zhou $X$. Tomato yellow leaf curl virus $\mathrm{V} 2$ interacts with host histone deacetylase 6 to suppress methylation-mediated transcriptional gene silencing in plants. J Virol. 2018;92(18):e00036-e118.

42. Coursey T, Milutinovic M, Regedanz E, Brkljacic J, Bisaro DM. Arabidopsis histone reader EMSY-LIKE 1 binds H3K36 and suppresses geminivirus infection. J Virol. 2018:92(16):e00219-e318.

43. Sahu PP, Sharma N, Puranik S, Chakraborty S, Prasad M. Tomato 26S Proteasome subunit RPT4a regulates ToLCNDV transcription and activates hypersensitive response in tomato. Sci Rep. 2016;6:27078.

44. Seemanpillai M, Dry I, Randles J, Rezaian A. Transcriptional silencing of geminiviral promoter-driven transgenes following homologous virus infection. Mol Plant Microbe Interact. 2003:16(5):429-38.

45. Basu S, Kumar Kushwaha N, Kumar Singh A, Pankaj Sahu P, Vinoth Kumar R, Chakraborty S. Dynamics of a geminivirus-encoded pre-coat protein and host RNA-dependent RNA polymerase 1 in regulating symptom recovery in tobacco. J Exp Bot. 2018;69(8):2085-102.

46. Prakash V, Singh A, Singh AK, Dalmay T, Chakraborty S. Tobacco RNAdependent RNA polymerase 1 affects the expression of defence-related genes in Nicotiana benthamiana upon Tomato leaf curl Gujarat virus infection. Planta. 2020;252(1):11.

47. Pooggin M, Shivaprasad PV, Veluthambi K, Hohn T. RNAi targeting of DNA virus in plants. Nat Biotechnol. 2003;21(2):131-2.

48. Rodríguez-Negrete EA, Carrillo-Tripp J, Rivera-Bustamante RF. RNA silencing against geminivirus: complementary action of posttranscriptional gene silencing and transcriptional gene silencing in host recovery. J Virol. 2009;83(3):1332-40.

49. Li J, Yang Z, Yu B, Liu J, Chen X. Methylation protects miRNAs and siRNAs from a 3'-end uridylation activity in Arabidopsis. Curr Biol. 2005;15(16):1501-7.
50. Brodersen $P$, Voinnet $O$. The diversity of RNA silencing pathways in plants. Trends Genet. 2006;22(5):268-80.

51. Bisaro DM. Silencing suppression by geminivirus proteins. Virology. 2006;344(1):158-68.

52. Ye J, Yang J, Sun Y, Zhao P, Gao S, Jung C, et al. Geminivirus activates ASYMMETRIC LEAVES 2 to accelerate cytoplasmic DCP2-mediated mRNA turnover and weakens RNA silencing in arabidopsis. PLoS Pathog. 2015;11(10):e1005196.

53. Li F, Huang C, Li Z, Zhou X. Suppression of RNA silencing by a plant DNA virus satellite requires a host calmodulin-like protein to repress RDR6 expression. PLoS Pathog. 2014;10(2):e1003921.

54. Li F, Zhao N, Li Z, Xu X, Wang Y, Yang X, et al. A calmodulin-like protein suppresses RNA silencing and promotes geminivirus infection by degrading SGS3 via the autophagy pathway in Nicotiana benthamiana. PLOS Pathog. 2017;13(2):e1006213.

55. Wang Y, Dang M, Hou H, Mei Y, Qian Y, Zhou X. Identification of an RNA silencing suppressor encoded by a mastrevirus. J Gen Virol. 2014;95(Pt 9):2082-8.

56. Eini $\mathrm{O}$. A betasatellite-encoded protein regulates key components of gene silencing system in plants. Mol Biol (Mosk). 2017;51(4):656-63.

57. Ismayil A, Haxim Y, Wang Y, Li H, Qian L, Han T, et al. Cotton Leaf Curl Multan virus C4 protein suppresses both transcriptional and posttranscriptional gene silencing by interacting with SAM synthetase. PLoS Pathog. 2018;14(8):e1007282.

58. Roeder S, Dreschler K, Wirtz M, Cristescu SM, van Harren FJ, Hell R, et al. SAM levels, gene expression of SAM synthetase, methionine synthase and ACC oxidase, and ethylene emission from N. suaveolens flowers. Plant Mol Biol. 2009;70(5):535-46.

59. Guha D, Poornima Priyadarshini CG, Purakayastha A, Thippeswamy R, Lakshmikanth M, Savithri HS. Biochemical characterization of C4 protein of Cotton leaf curl Kokhran Virus-Dabawali. Biochim Biophys Acta. 2013;1830(6):3734-44.

60. Abel PP, Nelson RS, De B, Hoffmann N, Rogers SG, Fraley RT, et al. Delay of disease development in transgenic plants that express the tobacco mosaic virus coat protein gene. Science. 1986;232(4751):738-43.

61. KunikT, Salomon R, Zamir D, Navot N, Zeidan M, Michelson I, et al. Transgenic tomato plants expressing the tomato yellow leaf curl virus capsid protein are resistant to the virus. Biotechnology (N Y). 1994;12(5):500-4.

62. Singh A, Taneja J, Dasgupta I, Mukherjee SK. Development of plants resistant to tomato geminiviruses using artificial trans-acting small interfering RNA. Mol Plant Pathol. 2015;16(7):724-34.

63. Namgial T, Kaldis A, Chakraborty S, Voloudakis A. Topical application of double-stranded RNA molecules containing sequences of Tomato leaf curl virus and Cucumber mosaic virus confers protection against the cognate viruses. Physiol Mol Plant Pathol. 2019;108:101432.

64. Wang J, Mei J, Ren G. Plant microRNAs: biogenesis, homeostasis, and degradation. Front Plant Sci. 2019;10:360.

65. Amin I, Patil BL, Briddon RW, Mansoor S, Fauquet CM. A common set of developmental miRNAs are upregulated in Nicotiana benthamiana by diverse begomoviruses. Virol J. 2011;8:143.

66. Chellappan P, Vanitharani R, Fauquet CM. MicroRNA-binding viral protein interferes with Arabidopsis development. Proc Natl Acad Sci U S A. 2005;102(29):10381-6.

67. Miozzi L, Napoli C, Sardo L, Accotto GP. Transcriptomics of the interaction between the monopartite phloem-limited geminivirus tomato yellow leaf curl Sardinia virus and Solanum lycopersicum highlights a role for plant hormones, autophagy and plant immune system fine tuning during infection. PLOS ONE. 2014;9(2):e89951.

68. Patwa N, Nithin C, Bahadur RP, Basak J. Identification and characterization of differentially expressed Phaseolus vulgaris miRNAs and their targets during mungbean yellow mosaic India virus infection reveals new insight into Phaseolus-MYMIV interaction. Genomics. 2019;111(6):1333-42.

69. Xiao B, Yang X, Ye CY, Liu Y, Yan C, Wang Y, et al. A diverse set of miRNAs responsive to begomovirus-associated betasatellite in Nicotiana benthamiana. BMC Plant Biol. 2014;14:60.

70. Naqvi AR, Choudhury NR, Mukherjee SK, Haq QM. In silico analysis reveals that several tomato microRNA/microRNA* sequences exhibit propensity to bind to tomato leaf curl virus (ToLCV) associated 
genomes and most of their encoded open reading frames (ORFs). Plant Physiol Biochem. 2011;49(1):13-7.

71. Vu TV, Choudhury NR, Mukherjee SK. Transgenic tomato plants expressing artificial microRNAs for silencing the pre-coat and coat proteins of a begomovirus, Tomato leaf curl New Delhi virus, show tolerance to virus infection. Virus Res. 2013;172(1-2):35-45.

72. Akmal M, Baig MS, Khan JA. Suppression of cotton leaf curl disease symptoms in Gossypium hirsutum through over expression of hostencoded miRNAs. J Biotechnol. 2017;263:21-9.

73. Ramesh SV, Gupta GK, Husain SM. Soybean (Glycine max) micrornas display proclivity to repress begomovirus genomes. Curr Sci. 2016;110:424-8

74. Kis $\mathrm{A}$, Tholt $\mathrm{G}$, Ivanics $\mathrm{M}$, Várallyay É, Jenes B, Havelda Z. Polycistronic artificial miRNA-mediated resistance to Wheat dwarf virus in barley is highly efficient at low temperature. Mol Plant Pathol. 2016;17(3):427-37.

75. Sharma N, Prasad M. Silencing AC1 of Tomato leaf curl virus using artificial microRNA confers resistance to leaf curl disease in transgenic tomato. Plant Cell Rep. 2020;39(11):1565-79.

76. Ramesh SV, Chouhan BS, Kumar G, Praveen S, Chand S. Expression dynamics of Glycine max (L.) Merrill microRNAs (miRNAs) and their targets during Mungbean yellow mosaic India virus (MYMIV) infection. Physiol Mol Plant Pathol. 2017;100:13-22.

77. Adams EHG, Spoel SH. The ubiquitin-proteasome system as a transcriptional regulator of plant immunity. J Exp Bot. 2018;69(19):4529-37.

78. Pauwels L, Goossens A. The JAZ proteins: a crucial interface in the jasmonate signaling cascade. Plant Cell. 2011;23(9):3089-100.

79. Shen Q, Hu T, Bao M, Cao L, Zhang H, Song F, et al. Tobacco RING E3 ligase NtRFP1 mediates ubiquitination and proteasomal degradation of a geminivirus-encoded $\beta C 1$. Mol Plant. 2016;9(6):911-25.

80. Li F, Zhang M, Zhang C, Zhou X. Nuclear autophagy degrades a geminivirus nuclear protein to restrict viral infection in solanaceous plants. New Phytol. 2020;225(4):1746-61.

81. Gorovits R, Moshe A, Kolot M, Sobol I, Czosnek H. Progressive aggregation of Tomato yellow leaf curl virus coat protein in systemically infected tomato plants, susceptible and resistant to the virus. Virus Res. 2013;171(1):33-43.

82. Maio F, Arroyo-Mateos M, Bobay BG, Bejarano ER, Prins M, van den Burg HA. A lysine residue essential for geminivirus replication also controls nuclear localization of the tomato yellow leaf curl virus rep protein. J Virol. 2019;93(10):e01910-e1918.

83. Gorovits R, Czosnek H. The involvement of heat shock proteins in the establishment of tomato yellow leaf curl virus infection. Front Plant Sci. 2017;8:355.

84. Lai J, Chen H, Teng K, Zhao Q, Zhang Z, Li Y, et al. RKP, a RING finger E3 ligase induced by BSCTV C4 protein, affects geminivirus infection by regulation of the plant cell cycle. Plant J. 2009;57(5):905-17.

85. Czosnek H, Eybishtz A, Sade D, Gorovits R, Sobol I, Bejarano E, et al. Discovering host genes involved in the infection by the Tomato Yellow Leaf Curl Virus complex and in the establishment of resistance to the virus using Tobacco Rattle Virus-based post transcriptional gene silencing. Viruses. 2013;5(3):998-1022.

86. Lozano-Durán R, Rosas-Díaz T, Gusmaroli G, Luna AP, Taconnat L, Deng XW, et al. Geminiviruses subvert ubiquitination by altering CSN-mediated derubylation of SCF E3 ligase complexes and inhibit jasmonate signaling in Arabidopsis thaliana. Plant Cell. 2011;23(3):1014-32.

87. Jia Q, Liu N, Xie K, Dai Y, Han S, Zhao X, et al. CLCuMuB $\beta C 1$ subverts ubiquitination by interacting with NbSKP1s to enhance geminivirus infection in nicotiana benthamiana. PLoS Pathog. 2016;12(6):e1005668.

88. Eini O, Dogra S, Selth LA, Dry IB, Randles JW, Rezaian MA. Interaction with a host ubiquitin-conjugating enzyme is required for the pathogenicity of a geminiviral DNA beta satellite. Mol Plant Microbe Interact. 2009;22(6):737-46.

89. Camborde L, Planchais S, Tournier V, Jakubiec A, Drugeon G, Lacassagne $\mathrm{E}$, et al. The ubiquitin-proteasome system regulates the accumulation of Turnip yellow mosaic virus RNA-dependent RNA polymerase during viral infection. Plant Cell. 2010;22(9):3142-52.

90. Reichel C, Beachy RN. Degradation of tobacco mosaic virus movement protein by the 26S proteasome. J Virol. 2000;74(7):3330-7.

91. Nair A, Chatterjee KS, Jha V, Das R, Shivaprasad PV. Stability of Begomoviral pathogenicity determinant $\beta C 1$ is modulated by mutually antagonistic SUMOylation and SIM interactions. BMC Biol. 2020;18(1):110.
92. van den Burg HA, Kini RK, Schuurink RC, Takken FL. Arabidopsis small ubiquitin-like modifier paralogs have distinct functions in development and defense. Plant Cell. 2010;22(6):1998-2016.

93. Mazur MJ, van den Burg HA. Global SUMO proteome responses guide gene regulation, mRNA biogenesis, and plant stress responses. Front Plant Sci. 2012;3:215.

94. Castillo AG, Kong LJ, Hanley-Bowdoin L, Bejarano ER. Interaction between a geminivirus replication protein and the plant sumoylation system. J Virol. 2004;78(6):2758-69.

95. Sánchez-Durán MA, Dallas MB, Ascencio-Ibañez JT, Reyes MI, ArroyoMateos M, Ruiz-Albert J, et al. Interaction between geminivirus replication protein and the SUMO-conjugating enzyme is required for viral infection. J Virol. 2011:85(19):9789-800.

96. Xiong R, Wang A. SCE1, the SUMO-conjugating enzyme in plants that interacts with NIb, the RNA-dependent RNA polymerase of Turnip mosaic virus, is required for viral infection. J Virol. 2013;87(8):4704-15.

97. Arroyo-Mateos M, Sabarit B, Maio F, Sánchez-Durán MA, Rosas-Díaz T, Prins $\mathrm{M}$, et al. Geminivirus replication protein impairs SUMO conjugation of proliferating cellular nuclear antigen at two acceptor sites. J Virol. 2018;92(18):e00611-e618.

98. Haxim Y, Ismayil A, Jia Q, Wang Y, Zheng X, Chen T, et al. Autophagy functions as an antiviral mechanism against geminiviruses in plants. Elife. 2017;6:e23897.

99. Hafrén A, Macia JL, Love AJ, Milner JJ, Drucker M, Hofius D. Selective autophagy limits cauliflower mosaic virus infection by NBR1-mediated targeting of viral capsid protein and particles. Proc Natl Acad Sci U S A. 2017:114(10):E2026-35.

100. Ismayil A, Yang M, Haxim Y, Wang Y, Li J, Han L, et al. Cotton leaf curl multan virus $\beta C 1$ protein induces autophagy by disrupting the interaction of autophagy-related protein 3 with glyceraldehyde3-phosphate dehydrogenases. Plant Cell. 2020;32(4):1124-35.

101. Breiden M, Simon R. Q\&A: how does peptide signaling direct plant development? BMC Biol. 2016;14:58.

102. Santos AA, Carvalho CM, Florentino LH, Ramos HJ, Fontes EP. Conserved threonine residues within the A-loop of the receptor NIK differentially regulate the kinase function required for antiviral signaling. PLoS ONE. 2009;4(6):e5781.

103. Shen Q, Liu Z, Song F, Xie Q, Hanley-Bowdoin L, Zhou X. Tomato SISnRK 1 protein interacts with and phosphorylates $\beta C 1$, a pathogenesis protein encoded by a geminivirus $\beta$-satellite. Plant Physiol. 2011;157(3):1394-406.

104. Hu T, Huang C, He Y, Castillo-González C, Gui X, Wang Y, et al. BC1 protein encoded in geminivirus satellite concertedly targets MKK2 and MPK4 to counter host defense. PLoS Pathog. 2019;15(4):e1007728.

105. Baena-González E, Rolland F, Thevelein JM, Sheen J. A central integrator of transcription networks in plant stress and energy signalling. Nature. 2007:448(7156):938-42.

106. Shen W, Reyes MI, Hanley-Bowdoin L. Arabidopsis protein kinases GRIK1 and GRIK2 specifically activate SnRK1 by phosphorylating its activation loop. Plant Physiol. 2009;150(2):996-1005.

107. Shen W, Hanley-Bowdoin L. Geminivirus infection up-regulates the expression of two Arabidopsis protein kinases related to yeast SNF1- and mammalian AMPK-activating kinases. Plant Physiol. 2006;142(4):1642-55.

108. Zhong X, Wang ZQ, Xiao R, Cao L, Wang Y, Xie Y, et al. Mimic phosphorylation of a $\beta C 1$ protein encoded by TYLCCNB impairs its functions as a viral suppressor of RNA silencing and a symptom determinant. J Virol. 2017;91(16):e00300-e317.

109. Soto-Burgos J, Bassham DC. SnRK1 activates autophagy via the TOR signaling pathway in Arabidopsis thaliana. PLOS ONE. 2017;12(8):e0182591.

110. Son S, Oh CJ, An CS. Arabidopsis thaliana remorins interact with SnRK1 and play a role in susceptibility to beet curly top virus and beet severe curly top virus. Plant Pathol J. 2014;30(3):269-78.

111. Hao L, Wang H, Sunter G, Bisaro DM. Geminivirus AL2 and L2 proteins interact with and inactivate SNF1 kinase. Plant Cell. 2003;15(4):1034-48.

112. Shen W, Bobay BG, Greeley LA, Reyes MI, Rajabu CA, Blackburn RK, et al. Sucrose Nonfermenting 1-related protein kinase 1 phosphorylates a geminivirus rep protein to impair viral replication and infection. Plant Physiol. 2018;178(1):372-89. 
113. Meng $X$, Zhang S. MAPK cascades in plant disease resistance signaling. Annu Rev Phytopathol. 2013;51:245-66.

114. Asano T, Nguyen TH, Yasuda M, Sidiq Y, Nishimura K, Nakashita H, et al. Arabidopsis MAPKKK $\delta-1$ is required for full immunity against bacterial and fungal infection. J Exp Bot. 2020;71 (6):2085-97.

115. Patel A, Dey N, Chaudhuri S, Pal A. Molecular and biochemical characterization of a Vigna mungo MAP kinase associated with Mungbean Yellow Mosaic India Virus infection and deciphering its role in restricting the virus multiplication. Plant Sci. 2017:262:127-40.

116. Li Y, Qin L, Zhao J, Muhammad T, Cao H, Li H, et al. SIMAPK3 enhances tolerance to tomato yellow leaf curl virus (TYLCV) by regulating salicylic acid and jasmonic acid signaling in tomato (Solanum lycopersicum). PLOS ONE. 2017;12(2):e0172466.

117. Luan JB, Li JM, Varela N, Wang YL, Li FF, Bao YY, et al. Global analysis of the transcriptional response of whitefly to tomato yellow leaf curl China virus reveals the relationship of coevolved adaptations. J Virol. 2011;85(7):3330-40

118. Mei $Y$, Wang $Y$, Hu T, He Z, Zhou X. The C4 protein encoded by Tomato leaf curl Yunnan virus interferes with mitogen-activated protein kinase cascade-related defense responses through inhibiting the dissociation of the ERECTA/BKI1 complex. New Phytol. 2021;231(2):747-62.

119. Yang X, Deng F, Ramonell KM. Receptor-like kinases and receptor-like proteins: keys to pathogen recognition and defense signaling in plant innate immunity. Front Biol. 2012;7(2):155-66.

120. Tena $G$, Boudsocq $M$, Sheen J. Protein kinase signaling networks in plant innate immunity. Curr Opin Plant Biol. 2011;14(5):519-29.

121. Mariano AC, Andrade MO, Santos AA, Carolino SM, Oliveira ML, BaracatPereira MC, et al. Identification of a novel receptor-like protein kinase that interacts with a geminivirus nuclear shuttle protein. Virology. 2004;318(1):24-31.

122. Fontes EP, Santos AA, Luz DF, Waclawovsky AJ, Chory J. The geminivirus nuclear shuttle protein is a virulence factor that suppresses transmembrane receptor kinase activity. Genes Dev. 2004;18(20):2545-56.

123. Li H, Zeng R, Chen Z, Liu X, Cao Z, Xie Q, et al. S-acylation of a geminivirus C4 protein is essential for regulating the CLAVATA pathway in symptom determination. J Exp Bot. 2018;69(18):4459-68.

124. Rosas-Diaz T, Zhang D, Fan P, Wang L, Ding X, Jiang Y, et al. A virustargeted plant receptor-like kinase promotes cell-to-cell spread of RNAi. Proc Natl Acad Sci U S A. 2018;115(6):1388-93.

125. Bi H, Fan W, Zhang P. C4 Protein of sweet potato leaf curl virus regulates brassinosteroid signaling pathway through interaction with AtBIN2 and affects male fertility in arabidopsis. Front Plant Sci. 2017:8:1689.

126. Garnelo Gómez B, Zhang D, Rosas-Díaz T, Wei Y, Macho AP, LozanoDurán R. The C 4 protein from tomato yellow leaf curl virus can broadly interact with plant receptor-like kinases. Viruses. 2019;11(11):1009.

127. Mei Y, Zhang F, Wang M, Li F, Wang Y, Zhou X. Divergent symptoms caused by geminivirus-encoded $C 4$ proteins correlate with their ability to bind NbSKn. J Virol. 2020;94(20):e01307-e1320.

128. Florentino LH, Santos AA, Fontenelle MR, Pinheiro GL, Zerbini FM, Baracat-Pereira MC, et al. A PERK-like receptor kinase interacts with the geminivirus nuclear shuttle protein and potentiates viral infection. J Virol. 2006;80(13):6648-56.

129. Zeng R, Liu X, Yang C, Lai J. Geminivirus C4: interplaying with receptorlike kinases. Trends Plant Sci. 2018;23(12):1044-6.

130. Gray WM. Hormonal regulation of plant growth and development. PLoS Biol. 2004;2(9):E311.

131. Corrales-Gutierrez M, Medina-Puche L, Yu Y, Wang L, Ding X, Luna AP, et al. The C 4 protein from the geminivirus Tomato yellow leaf curl virus confers drought tolerance in Arabidopsis through an ABA-independent mechanism. Plant Biotechnol J. 2020;18(5):1121-3.

132. Ghosh D, Chakraborty S. Molecular interplay between phytohormones and geminiviruses: a saga of a never-ending arms race. J Exp Bot. 2021.

133. Ascencio-lbáñez JT, Sozzani R, Lee TJ, Chu TM, Wolfinger RD, Cella $R$, et al. Global analysis of Arabidopsis gene expression uncovers a complex array of changes impacting pathogen response and cell cycle during geminivirus infection. Plant Physiol. 2008;148(1):436-54.

134. Chen H, Zhang Z, Teng K, Lai J, Zhang Y, Huang Y, et al. Up-regulation of LSB1/GDU3 affects geminivirus infection by activating the salicylic acid pathway. Plant J. 2010;62(1):12-23.
135. Ali S, Khan M, Sahi S, Hassan M. Evaluation of plant extracts and salicylic acid against Bemisia tabaci and cotton leaf curl virus disease. Pak J Phytopathol. 2010;22:98-100.

136. Li T, Huang Y, Xu ZS, Wang F, Xiong AS. Salicylic acid-induced differential resistance to the Tomato yellow leaf curl virus among resistant and susceptible tomato cultivars. BMC Plant Biol. 2019;19(1):173.

137. Yang JY, Iwasaki M, Machida C, Machida Y, Zhou X, Chua NH. betaC1, the pathogenicity factor of TYLCCNV, interacts with AS1 to alter leaf development and suppress selective jasmonic acid responses. Genes Dev. 2008;22(18):2564-77.

138. Li R, Weldegergis BT, Li J, Jung C, Qu J, Sun Y, et al. Virulence factors of geminivirus interact with MYC2 to subvert plant resistance and promote vector performance. Plant Cell. 2014;26(12):4991-5008.

139. Zhang PJ, He YC, Zhao C, Ye ZH, Yu XP. Jasmonic acid-dependent defenses play a key role in defending tomato against bemisia tabaci nymphs, but not adults. Front Plant Sci. 2018;9:1065.

140. Naseem M, Kaltdorf M, Dandekar T. The nexus between growth and defence signalling: auxin and cytokinin modulate plant immune response pathways. J Exp Bot. 2015;66(16):4885-96.

141. Vinutha T, Vanchinathan S, Bansal N, Kumar G, Permar V, Watts A, et al. Tomato auxin biosynthesis/signaling is reprogrammed by the geminivirus to enhance its pathogenicity. Planta. 2020;252(4):51.

142. Liu Y, Liu Y, Spetz C, Li L, Wang X. Comparative transcriptome analysis in Triticum aestivum infecting wheat dwarf virus reveals the effects of viral infection on phytohormone and photosynthesis metabolism pathways. Phytopathol Res. 2020;2(1):3.

143. Baliji S, Lacatus G, Sunter $\mathrm{G}$. The interaction between geminivirus pathogenicity proteins and adenosine kinase leads to increased expression of primary cytokinin-responsive genes. Virology. 2010;402(2):238-47.

144. Park J, Lee HJ, Cheon CI, Kim SH, Hur YS, Auh CK, et al. The Arabidopsis thaliana homeobox gene ATHB12 is involved in symptom development caused by geminivirus infection. PLoS ONE. 2011;6(5):e20054.

145. Soitamo AJ, Jada B, Lehto K. Expression of geminiviral AC2 RNA silencing suppressor changes sugar and jasmonate responsive gene expression in transgenic tobacco plants. BMC Plant Biol. 2012;12:204.

146. Chandan RK, Singh AK, Patel S, Swain DM, Tuteja N, Jha G. Silencing of tomato CTR1 provides enhanced tolerance against Tomato leaf curl virus infection. Plant Signal Behav. 2019;14(3):e1565595.

147. Krake LR, Rezaian MA, Dry IB. Expression of the tomato leaf curl geminivirus $\mathrm{C} 4$ gene produces viruslike symptoms in transgenic plants. Mol Plant-Microbe Interact. 1998;11(5):413-7.

148. Mills-Lujan K, Deom CM. Geminivirus C4 protein alters Arabidopsis development. Protoplasma. 2010;239(1-4):95-110.

149. Piroux N, Saunders K, Page A, Stanley J. Geminivirus pathogenicity protein C4 interacts with Arabidopsis thaliana shaggy-related protein kinase AtSKeta, a component of the brassinosteroid signalling pathway. Virology. 2007;362(2):428-40.

150. Villa-Ruano N, Velásquez-Valle R, Zepeda-Vallejo LG, Pérez-Hernández N, Velázquez-Ponce M, Arcos-Adame VM, et al. 1)H NMR-based metabolomic profiling for identification of metabolites in Capsicum annuum Cv. mirasol infected by beet mild curly top virus (BMCTV). Food Res Int. 2018;106:870-7.

151. Mahmoudabadi G, Milo R, Phillips R. Energetic cost of building a virus. Proc Natl Acad Sci U S A. 2017;114(22):E4324-33.

152. Srivastava S, Bisht $H$, Sidhu OP, Srivastava A, Singh PC, Pandey RM, et al. Changes in the metabolome and histopathology of Amaranthus hypochondriacus $L$. in response to Ageratum enation virus infection. Phytochemistry. 2012;80:8-16.

153. Leal N, Lastra R. Altered metabolism of tomato plants infected with tomato yellow mosaic virus. Physiol Plant Pathol. 1984;24(1):1-7.

154. Kushwaha N, Sahu PP, Prasad M, Chakraborty S. Chilli leaf curl virus infection highlights the differential expression of genes involved in protein homeostasis and defense in resistant chilli plants. Appl Microbiol Biotechnol. 2015:99(11):4757-70.

155. Kushwaha NK, Mansi B, Sahu PP, Prasad M, Chakrabroty S. Chilli leaf curl virus infection downregulates the expression of the genes encoding chloroplast proteins and stress-related proteins. Physiol Mol Biol Plants. 2019;25(5):1185-96.

156. Cui H, Sun Y, Chen F, Zhang Y, Ge F. Elevated $O 3$ and TYLCV infection reduce the suitability of tomato as a host for the whitefly bemisia tabaci. Int J Mol Sci. 2016:17(12):1964. 
157. Bleeker PM, Diergaarde PJ, Ament K, Guerra J, Weidner M, Schütz S, et al. The role of specific tomato volatiles in tomato-whitefly interaction. Plant Physiol. 2009;151(2):925-35.

158. Zhang W, McAuslane HJ, Schuster DJ. Repellency of ginger oil to Bemisia argentifolii (Homoptera: Aleyrodidae) on tomato. J Econ Entomol. 2004;97(4):1310-8.

159. Luan JB, Yao DM, Zhang T, Walling LL, Yang M, Wang YJ, et al. Suppression of terpenoid synthesis in plants by a virus promotes its mutualism with vectors. Ecol Lett. 2013;16(3):390-8.

160. Ayliffe M, Sørensen CK. Plant nonhost resistance: paradigms and new environments. Curr Opin Plant Biol. 2019;50:104-13.

161. Seo YS, Jeon JS, Rojas MR, Gilbertson RL. Characterization of a novel Toll/interleukin-1 receptor (TIR)-TIR gene differentially expressed in common bean (Phaseolus vulgaris cv. Othello) undergoing a defence response to the geminivirus Bean dwarf mosaic virus. Mol Plant Pathol. 2007;8(2):151-62.

162. Lapidot M, Karniel U, Gelbart D, Fogel D, Evenor D, Kutsher Y, et al. A Novel Route Controlling Begomovirus Resistance by the Messenger RNA Surveillance Factor Pelota. PLoS Genet. 2015;11(10):e1005538.

163. García-Arenal F, Zerbini FM. Life on the edge: geminiviruses at the interface between crops and wild plant hosts. Annu Rev Virol. 2019;6(1):411-33.

164. Verlaan MG, Hutton SF, Ibrahem RM, Kormelink R, Visser RG, Scott JW, et al. The tomato yellow leaf curl virus resistance genes Ty- 1 and Ty-3 are allelic and code for DFDGD-class RNA-dependent RNA polymerases. PLoS Genet. 2013;9(3):e1003399.

165. Butterbach P, Verlaan MG, Dullemans A, Lohuis D, Visser RG, Bai Y, et al. Tomato yellow leaf curl virus resistance by Ty-1 involves increased cytosine methylation of viral genomes and is compromised by cucumber mosaic virus infection. Proc Natl Acad Sci U S A. 2014;111(35):12942-7.

166. Prasanna HC, Sinha DP, Rai GK, Krishna R, Kashyap SP, Singh NK, et al. Pyramiding Ty-2 and Ty-3 genes for resistance to monopartite and bipartite tomato leaf curl viruses of India. Plant Pathol. 2015;64(2):256-64.

167. Yamaguchi H, Ohnishi J, Saito A, Ohyama A, Nunome T, Miyatake K, et al. An NB-LRR gene, TYNBS1, is responsible for resistance mediated by the Ty-2 Begomovirus resistance locus of tomato. Theor Appl Genet. 2018;131(6):1345-62.

168. Anbinder I, Reuveni M, Azari R, Paran I, Nahon S, Shlomo H, et al. Molecular dissection of Tomato leaf curl virus resistance in tomato line TY172 derived from Solanum peruvianum. Theor Appl Genet. 2009;119(3):519-30.

169. Gill U, Scott JW, Shekasteband R, Ogundiwin E, Schuit C, Francis DM, et al. Ty-6, a major begomovirus resistance gene on chromosome 10, is effective against Tomato yellow leaf curl virus and Tomato mottle virus. Theor Appl Genet. 2019;132(5):1543-54.

170. Ji Y, Scott JW, Schuster DJ, Maxwell DP. Molecular Mapping of Ty-4, a New Tomato Yellow Leaf Curl Virus Resistance Locus on Chromosome 3 of Tomato. 2009;134(2):281.

171. Voorburg CM, Yan Z, Bergua-Vidal M, Wolters AA, Bai Y, Kormelink R. Ty-1, a universal resistance gene against geminiviruses that is compromised by co-replication of a betasatellite. Mol Plant Pathol. 2020;21 (2):160-72.

172. Singh RK, Rai N, Lima JM, Singh M, Singh SN, Kumar S. Genetic and molecular characterisations of Tomato leaf curl virus resistance in tomato (Solanum lycopersicum L.). J Horticult Sci Biotechnol. 2015;90(5):503-10.

173. Fregene M, Bernal A, Duque M, Dixon A, Tohme J. AFLP analysis of African cassava (Manihot esculenta Crantz) germplasm resistant to the cassava mosaic disease (CMD). Theor Appl Genet. 2000;100(5):678-85.

174. Fondong VN. The search for resistance to cassava mosaic geminiviruses: how much we have accomplished, and what lies ahead. Front Plant Sci. 2017;8:408.

175. Akano O, Dixon O, Mba C, Barrera E, Fregene M. Genetic mapping of a dominant gene conferring resistance to cassava mosaic disease. Theor Appl Genet. 2002;105(4):521-5.

176. Naqvi RZ, Zaidi SS, Akhtar KP, Strickler S, Woldemariam M, Mishra B, et al. Transcriptomics reveals multiple resistance mechanisms against cotton leaf curl disease in a naturally immune cotton species, Gossypium arboreum. Sci Rep. 2017;7(1):15880.

177. Nazeer W, Tipu AL, Ahmad S, Mahmood K, Mahmood A, Zhou B. Evaluation of cotton leaf curl virus resistance in $\mathrm{BC} 1, \mathrm{BC} 2$, and $\mathrm{BC} 3$ progenies from an interspecific cross between Gossypium arboreum and Gossypium hirsutum. PLoS ONE. 2014;9(11):e111861.

178. Rahman M, Hussain D, MalikTA, Zafar Y. Genetics of resistance to cotton leaf curl disease in Gossypium hirsutum. Plant Pathol. 2005;54(6):764-72.

179. Naveed K, Abbas A, Khan SA, Amrao L, Ali MA. Global status and future prospects of research in cotton leaf curl disease. Arch Phytopathol Plant Protect. 2018;51(7-8):323-37.

180. Seth T, Chattopadhyay A, Dutta S, Hazra P, Singh B. Genetic control of yellow vein mosaic virus disease in okra and its relationship with biochemical parameters. Euphytica. 2017;213(2):30.

181. Singh H, Joshi B, Khanna P, Gupta P. Breeding for field resistance to yellow vein mosaic in bhindi. Indian J Genet Plant Breed. 1962;22(2):137-44.

182. Thakur M. Inheritance of Resistance to Yellow Vein Mosaic (YVM) in a Cross of Okra Species, Abelmoschus esculentus and A. manihot ssp, Manihot. SABRAO J. 1976;8:69-73.

183. Dhankhar SK, Dhankhar BS, Yadava RK. Inheritance of resistance to yellow vein mosaic virus in an interspecific cross of okra (Abelmoschus esculentus). Indian J Agric Sci. 2005;75:87-9.

184. Pullaiah N, Reddy TB, Moses GJ, Reddy BM, Reddy DR. Inheritance of resistance to yellow vein mosaic virus in okra (Abelmoschus esculentus(L.) Moench). Indian J Genet Plant Breed. 1998;58(3):349-52.

185. Jambhale ND, Nerkar YS. Inheritance of resistance to Okra yellow vein mosaic disease in interspecific crosses of Abelmoschus. Theor Appl Genet. 1981;60(5):313-6.

186. Sharma BR, Dhillon TS. Genetics of resistance to yellow vein mosaic virus in interspecific crosses of okra. Genet Agraria. 1983;37:267-75.

187. Dutta OP. Breeding in Okra for Resistance to Yellow Vein Mosaic Virus and Enation Leaf Curl Virus. Annual Report, IHHR. 1984.

188. Blair MW, Rodriguez LM, Pedraza F, Morales F, Beebe S. Genetic mapping of the bean golden yellow mosaic geminivirus resistance gene bgm-1 and linkage with potyvirus resistance in common bean (Phaseolus vulgaris L.). Theor Appl Genet. 2007;114(2):261-71.

189. Velez JJ, Bassett MJ, Beaver JS, Molina A. Inheritance of resistance to bean golden mosaic virus in common bean. J Am Soc Horticult Sci. 1998;123(4):628.

190. Román MA, Castañeda AM, Sánchez JCA, Muñoz CGN, Beaver JS. Inheritance of normal pod development in bean golden yellow mosaic resistant common bean. J Am Soc Horticult Sci. 2004:129(4):549.

191. Monci F, García-Andrés S, Maldonado JA, Moriones E. Resistance to monopartite begomoviruses associated with the bean leaf crumple disease in phaseolus vulgaris controlled by a single dominant gene. Phytopathology. 2005;95(7):819-26.

192. Larsen RC, Miklas PN. Generation and molecular mapping of a sequence characterized amplified region marker linked with the bct gene for resistance to beet curly top virus in common bean. Phytopathology. 2004;94(4):320-5.

193. Islam S, Munshi AD, Mandal B, Kumar R, Behera TK. Genetics of resistance in Luffa cylindrica Roem. against Tomato leaf curl New Delhi virus. Euphytica. 2010;174(1):83-9.

194. Islam S, Anilabh Das M, Verma M, Arya L, Mandal B, Tusar Kanti B, et al. Screening of Luffa cylindrica Roem. for resistance against Tomato Leaf Curl New Delhi Virus, inheritance of resistance, and identification of SRAP markers linked to the single dominant resistance gene. J Horticult Sci Biotechnol. 2011;86(6):661-7.

195. Sáez C, Esteras C, Martínez C, Ferriol M, Dhillon NPS, López C, et al. Resistance to tomato leaf curl New Delhi virus in melon is controlled by a major QTL located in chromosome 11. Plant Cell Rep. 2017;36(10):1571-84.

196. Sáez C, Martínez C, Montero-Pau J, Esteras C, Sifres A, Blanca J, et al. A major QTL located in chromosome 8 of cucurbita moschata is responsible for resistance to tomato leaf curl new Delhi virus. Front Plant Sci. 2020;11:207.

197. Moreno AB, López-Moya JJ. When viruses play team sports: mixed infections in plants. Phytopathology. 2020;110(1):29-48.

198. Singh RP. Genetic association of gene Bdv1 for tolerance to barley yellow dwarf virus with genes Lr34 and Yr18 for adult plant resistance to rusts in bread wheat. Plant Dis. 1993;77:1103-6.

199. Jones JD, Dangl JL. The plant immune system. Nature. 2006:444(7117):323-9. 
200. Garrido-Ramirez ER, Sudarshana MR, Lucas WJ, Gilbertson RL. Bean dwarf mosaic virus BV1 protein is a determinant of the hypersensitive response and avirulence in Phaseolus vulgaris. Mol Plant Microbe Interact. 2000;13(11):1184-94.

201. van Wezel R, Dong X, Blake P, Stanley J, Hong Y. Differential roles of geminivirus Rep and AC4 (C4) in the induction of necrosis in Nicotiana benthamiana. Mol Plant Pathol. 2002;3(6):461-71.

202. Sharma P, Ikegami M. Tomato leaf curl Java virus V2 protein is a determinant of virulence, hypersensitive response and suppression of posttranscriptional gene silencing. Virology. 2010;396(1):85-93.

203. Matić S, Pegoraro M, Noris E. The C2 protein of tomato yellow leaf curl Sardinia virus acts as a pathogenicity determinant and a 16-amino acid domain is responsible for inducing a hypersensitive response in plants. Virus Res. 2016;215:12-9.

204. Mei Y, Ma Z, Wang Y, Zhou X. Geminivirus C4 antagonizes the HIR1-mediated hypersensitive response by inhibiting the HIR1 selfinteraction and promoting degradation of the protein. New Phytol. 2020;225(3):1311-26.

205. Sowden RG, Watson SJ, Jarvis P. The role of chloroplasts in plant pathology. Essays Biochem. 2018;62(1):21-39.

206. Bhattacharyya D, Chakraborty S. Chloroplast: the Trojan horse in plantvirus interaction. Mol Plant Pathol. 2018;19(2):504-18.

207. Gnanasekaran P, Ponnusamy K, Chakraborty S. A geminivirus betasatellite encoded $\beta C 1$ protein interacts with PsbP and subverts PsbP-mediated antiviral defence in plants. Mol Plant Pathol. 2019;20(7):943-60.

208. Yuan X, Wang H, Cai J, Li D, Song F. NAC transcription factors in plant immunity. Phytopathology Research. 2019;1(1):3.

209. Xie Q, Sanz-Burgos AP, Guo H, García JA, Gutiérrez C. GRAB proteins, novel members of the NAC domain family, isolated by their interaction with a geminivirus protein. Plant Mol Biol. 1999;39(4):647-56.
210. Chung HY, Sunter G. Interaction between the transcription factor AtTIFY4B and begomovirus AL2 protein impacts pathogenicity. Plant Mol Biol. 2014;86(1-2):185-200.

211. Ji X, Zhang H, Zhang Y, Wang Y, Gao C. Establishing a CRISPR-Cas-like immune system conferring DNA virus resistance in plants. Nat Plants. 2015;1:15144.

212. Baltes NJ, Hummel AW, Konecna E, Cegan R, Bruns AN, Bisaro DM, et al. Conferring resistance to geminiviruses with the CRISPR-Cas prokaryotic immune system. Nat Plants. 2015;1(10):15145.

213. Ali Z, Abulfaraj A, Idris A, Ali S, Tashkandi M, Mahfouz MM. CRISPR/Cas9mediated viral interference in plants. Genome Biol. 2015;16:238.

214. Chaparro-Garcia A, Kamoun S, Nekrasov V. Boosting plant immunity with CRISPR/Cas. Genome Biol. 2015;16:254.

215. Mehta D, Sturchler A, Anjanappa RB, Zaidi SS, Hirsch-Hoffmann M, Gruissem W, et al. Linking CRISPR-Cas9 interference in cassava to the evolution of editing-resistant geminiviruses. Genome Biol. 2019;20(1):80.

216. Ali Z, Ali S, Tashkandi M, Zaidi SS, Mahfouz MM. CRISPR/Cas9-mediated immunity to geminiviruses: differential interference and evasion. Sci Rep. 2016;6:26912.

217. Ellison EE, Nagalakshmi U, Gamo ME, Huang PJ, Dinesh-Kumar S, Voytas DF. Multiplexed heritable gene editing using RNA viruses and mobile single guide RNAs (vol 6, pg 620, 2020). Nat Plants. 2021;7(1):99-.

218. Roy A, Zhai Y, Ortiz J, Neff M, Mandal B, Mukherjee SK, et al. Multiplexed editing of a begomovirus genome restricts escape mutant formation and disease development. PLoS ONE. 2019;14(10):e0223765.

\section{Publisher's Note}

Springer Nature remains neutral with regard to jurisdictional claims in published maps and institutional affiliations.
Ready to submit your research? Choose BMC and benefit from:

- fast, convenient online submission

- thorough peer review by experienced researchers in your field

- rapid publication on acceptance

- support for research data, including large and complex data types

- gold Open Access which fosters wider collaboration and increased citations

- maximum visibility for your research: over 100M website views per year

At BMC, research is always in progress.

Learn more biomedcentral.com/submissions 